\title{
Application of Satellite-Derived Ocean Surface Winds to the Detection of Weather Systems and the Prediction of Near-Ocean Surface Winds around Hawaii
}

\author{
Hsi-Chyi Yeh", 2,* \\ ${ }^{1}$ Department of Meteorology, University of Hawaii at Manoa, Honolulu, USA \\ ${ }^{2}$ Department of Computer Science and Information Engineering, Aletheia University, Tamshui, Taiwan
}

Received 14 September 2009, accepted 29 March 2010

\begin{abstract}
The Hawaiian Island chain is surrounded by the open ocean and is an ideal place to conduct the application of QuikSCAT satellite-derived ocean surface winds to the detection of weather systems. With the help of QuikSCAT winds, the associated circulation of the weather systems over the open ocean around Hawaii can be identified. In this study, the obvious cyclonic circulation associated with a Kona storm, the significant wind shift and wind confluence related to the surface cold front, and the anticyclonic circulation related to high-pressure systems for both a strong-wind event and a trade-wind condition are revealed over the open ocean through QuikSCAT winds. The propagation of a cold frontal boundary, defined by the wind shift and wind confluence, also can be clearly detected using the reanalyzed ocean-surface winds.

With the assimilation of QuikSCAT winds into the WRF 3D-Var system, the under-estimation of near-ocean surface winds in the Hawaiian Islands and the surrounding ocean by the Global Forecasting System (GFS) and NCEP reanalysis can be improved in the analyzed low-level winds and the associated short-term forecast, including the effects of the Island obstacle on near-ocean surface winds. To statistically evaluate the prediction of near-ocean surface winds under the influence of the most frequent weather systems and events in Hawaii, the numerical weather predictions with/without assimilated QuikSCAT wind data are performed. The results reveal that the predicted $10-\mathrm{m}$ wind speed/direction during the 24-hr forecast results in a relatively smaller mean squared error (MSE) with assimilated QuikSCAT winds as compared with the GFS/NCEP-FNL run for the ocean surrounding Hawaii.
\end{abstract}

Key words: QuikSCAT winds, Kona storm, WRF 3D-Var

Citation: Yeh, H.C., 2010: Application of satellite-derived ocean surface winds to the detection of weather systems and the prediction of near-ocean surface winds around Hawaii. Terr. Atmos. Ocean. Sci., 21, 955-969, doi: 10.3319/TAO.2010.03.29.01(A)

\section{INTRODUCTION}

The Hawaiian Islands are a unique geographical location: complicated island topography is surrounded by the open ocean, and the weather systems come from extratropical, subtropical, and tropical regions. The paucity of weather observations over the surrounding ocean poses a challenge for weather analyses and for the numerical weather predictions of the evolution and propagation of weather systems over the ocean of Hawaii (Kodama and Businger 1998). With the availability of satellite-derived ocean surface winds, improvement in the analyses of weather systems

\footnotetext{
* Corresponding author

E-mail:yehhc123@gmail.com
}

and the associated predictions around Hawaii deserves further studied.

The satellite-derived ocean surface wind data - from the European Remote-Sensing Satellites 1 and 2 (ERS-1 and ERS-2)(Liu and Chan 1999), the NASA Scatterometer (NSCAT)(Leidner et al. 2003) and QuikSCAT/Sea Winds (Liu et al. 1998, 2000; Sharp et al. 2002) - were used to improve the analysis of weather systems and numerical simulations, especially in the global models (Atlas et al. 2001). Liu and Chan (1999) used the ERS-1 and ERS-2 to show that tropical cyclones occurring over the western North Pacific and the North Atlantic are of different sizes. Their results also showed the seasonal variation of the mean tropical cyclone size. Leidner et al. (2003) showed that the NSCAT 
data can be used to improve the depiction of the surface wind field in both tropical and extratropical cyclones, and thus provide early detection of both types of cyclones.

As in previous studies (Liu and Chan 1999; Leidner et al. 2003), satellite-derived oceanic winds can provide useful information about tropical cyclones, especially in the early stage. Even though these data may not be helpful in predicting hurricanes or typhoons with derived wind speed $<20-30 \mathrm{~m} \mathrm{~s}^{-1}$, this constraint of the maximum wind speed can be ignored in studying the other weather systems. For example, the kinematic properties and the evolution of the surface Mei-yu front in the vicinity of Taiwan were properly detected over the ocean by QuikSCAT winds (Yeh et al. 2002; Yeh and Chen 2004). In the Hawaiian Island chain, tropical cyclones are infrequent. Thus, the frequent weather systems and weather episodes, including a Kona storm (5 April 2008), a surface cold front (11 April 2008), and a strong-wind event (13 February 2001) and a trade-wind condition (8 May 2008), are examined using QuikSCAT winds.

Based on case studies, Chelton et al. (2006) showed that the analyses of 10-m winds from the NCEP and ECMWF global NWP models considerably underestimated the spatial variability of the wind field on scales smaller than $1000 \mathrm{~km}$ compared with the structure determined from QuikSCAT winds. With the implementation of the QuikSCAT data assimilation, the accuracies of the $10-\mathrm{m}$ wind analysis from the NCEP and ECMWF global NWP model can be improved. Meanwhile, the QuikSCAT data are assimilated into the global models in smoothed form by averaging the $25-\mathrm{km}$ measurements of radar backscatter with a $50-\mathrm{km}$ resolution for ECMWF and $0.5^{\circ}$ for the NCEP model ( $1^{\circ}$ prior to 11 March 2003)(Chelton et al. 2006) to improve the accuracy of the top-ranked wind direction ambiguity for the lower resolution retrievals and reduce the higher noise that is present in the $25-\mathrm{km}$ resolution retrievals near nadir (Portabella and Stoffelen 2004; Chelton and Freilich 2005). However, QuikSCAT winds used by the global models through data assimilation is underutilized; it is more likely related to assign overly pessimistic error estimates to QuikSCAT winds in the global forecast and analysis. To assign larger observation errors for QuikSCAT winds, during the process of data assimilation, may ameliorate inconsistencies between the coarse-resolution operational model systems and the relatively high-resolution scatterometer measurements (Isaksen and Janssen 2004). Down-weighting QuikSCAT winds by assigning pessimistic error estimate may also be necessary to avoid the disruption of the model as assimilated other input data (Leidner et al. 2003). For this study, only QuikSCAT winds are assimilated with the global analyses and serve as the initial conditions for the mesoscale model. The horizontal resolution for mesoscale model domains (18 and $6 \mathrm{~km}$ ) is higher than that of QuikSCAT winds and the global analyses. The under-utilization of QuikSCAT winds in the global model can be improved. Also, the effects of the Island obstacle on near-ocean surface winds over Hawaii will be revealed.

As analyzed by Yang et al. (2005), the mean wind speed at the 1000-hPa level inland and over the surrounding ocean of the Hawaiian Islands had a minimum at Hilo (Fig. 1a) during the summer trade wind conditions analyzed by the NCEP $2.5^{\circ}$ global reanalysis during July - August 1990. Here the $1^{\circ}$ Global Forecasting System (GFS) analysis and a $1^{\circ}$ NCEP reanalysis are also utilized to calculate the mean wind speed (Fig. 1b) at the 1000-hPa level for four frequent weather conditions in Hawaii; the weakest wind speed $\left(<5 \mathrm{~m} \mathrm{~s}^{-1}\right)$ regime occurs over the Hawaiian Islands and surrounding ocean. This is consistent with the mean 1000-hPa level wind speeds of 4.1 and $5.8 \mathrm{~m} \mathrm{~s}^{-1} \mathrm{cal}-$ culated by the local soundings at Hilo and Lihue (Fig. 1b), (a)

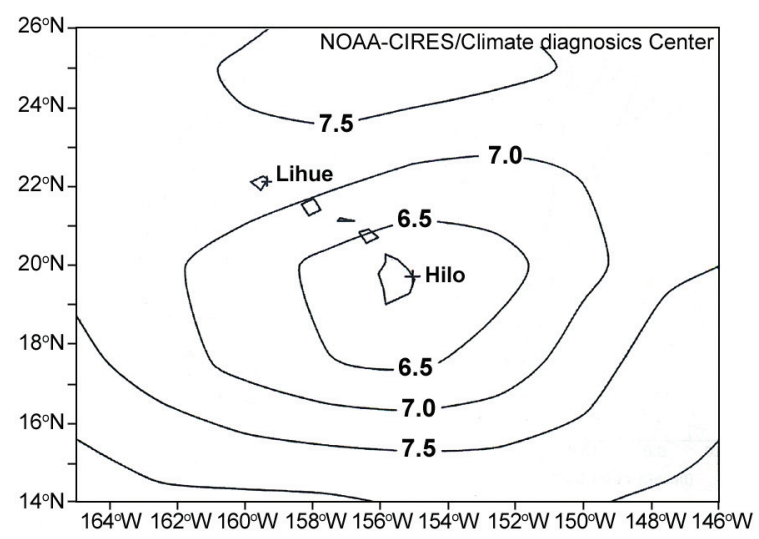

(b)

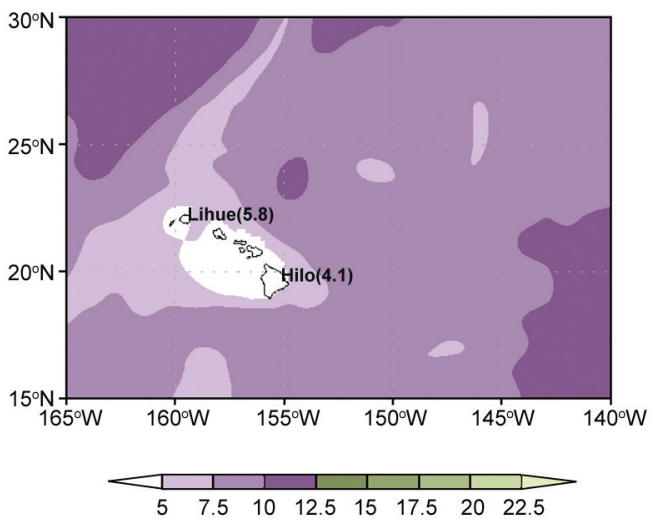

Fig. 1. (a) The mean wind speed $\left(\mathrm{m} \mathrm{s}^{-1}\right)$ of July and August 1990 at the 1000 -hPa level from $2.5^{\circ}$ NCEP-NCAR reanalysis data. Contour interval of $0.5 \mathrm{~m} \mathrm{~s}^{-1}$. The symbol "+" denotes the rawinsonde sites (Adapted from Yang et al. 2005). (b) The mean wind speed ( $\mathrm{m} \mathrm{s}^{-1}$ ) at the 1000-hPa level from four cases using $1^{\circ} \mathrm{GFS}$ and $1^{\circ} \mathrm{NCEP}$ reanalysis data. The number next to the Lihue and Hilo rawinsonde sites is related to the mean wind speed respectively for four cases at the same level. The shading starts from $2.5 \mathrm{~m} \mathrm{~s}^{-1}$ with a $2.5 \mathrm{~m} \mathrm{~s}^{-1}$ interval. 
respectively. Over the Hawaiian Islands, there are only two rawinsondes sites. One is at Lihue and the other is at Hilo. As showed by Yang et al. (2005), the low-level winds from Hilo soundings are greatly affected by the island blocking with weak speeds than those over the open ocean. Because of using the Hilo soundings, there is an area with weak mean trade wind speed (outlined by contour of $6.5 \mathrm{~m} \mathrm{~s}^{-1}$ ) extending about $400 \mathrm{~km}$ upstream of Hilo in the NCEP $2.5^{\circ}$ global reanalysis (Fig. 1a). The open ocean trade wind speed upstream of Hilo is underestimated. Therefore, the QuikSCAT winds are chosen and substituted to represent the circulation of the associated weather systems over the open ocean and improve the numerical simulation of near-ocean surface winds for frequent weather systems and events (a surface cold front, a Kona storm, a strengthened anticyclone with a strong-wind event, and a trade-wind condition) around Hawaii.

In this study, the data (QuikSCAT winds and buoy observations) and the methodology [Advanced Research WRF (ARW) model, the associated three-dimensional variational (3D-Var) data assimilation system, low-pass objective analysis, and statistical verifications] are briefly introduced in section 2. Detection of the weather systems over the open ocean by QuikSCAT winds is discussed in section 3. Impact of the assimilated QuikSCAT data on the low-level winds in the model initial conditions and the associated 24-hr near-ocean surface wind forecasting are presented and statistically verified in section 4 . The conclusions comprise section 5 .

\section{DATA AND METHODOLOGY}

\subsection{Data}

In this study, the QuikSCAT wind data are used to detect the weather systems over the open ocean around Hawaii and to improve the prediction of near-ocean surface winds. Data are collected twice daily and include ascending (1300 - 1700 UTC) and descending (0200 - 0400 UTC) $0.25^{\circ} \times$ $0.25^{\circ}$ retrieved data with blank areas over the open ocean and a daily map that covers $90 \%$ of the global ocean (Atlas et al. 2001).

For the rain effects on QuikSCAT winds, a rain flag is reported for each wind measurement in the near real time and standard datasets (Huddleston and Stiles 2000; Stiles and Yueh 2002). As suggested by Chelton et al. (2006), users are cautioned that QuikSCAT wind estimates alone can not be used to ascertain whether a rain-flagged observation is a valid estimate of the wind since high winds can be either valid or erroneous, depending on the true wind speed. To assess whether the true wind speed is high or low, additional information is required, either from in situ measurements as in the buoy comparisons or based on the judgment of an experienced analyst.
In this study, the reanalyzed ocean surface winds obtained from the low-pass objective analysis (Maddox 1980) of the version-3a QuikSCAT ocean winds (Donnelly et al. 1999) are incorporated into global data (GFS and NCEPFNL reanalysis) through WRF 3D-Var system. Because the accuracies of QuikSCAT winds are very similar to the accuracies of buoy measurements of near-surface winds (Chelton and Feilich 2005), the same observation errors used in the buoy observations are chosen for the reanalyzed oceansurface winds in the WRF 3D-Var system.

In addition to QuikSCAT winds, there are four buoy [B1 (51001), B2 (51002), B3 (51003), and B4 (51004)] observations (Fig. 2) around Hawaii from the National Data Buoy Center (NDBC): B1 (51001) located at $\left(23.445^{\circ} \mathrm{N}\right.$, $\left.162.279^{\circ} \mathrm{W}\right), \mathrm{B} 2(51002)$ located at $\left(17.191^{\circ} \mathrm{N}, 157.781^{\circ} \mathrm{W}\right)$, B3 (51003) located at $\left(19.087^{\circ} \mathrm{N}, 160.660^{\circ} \mathrm{W}\right)$, and $\mathrm{B} 4$ (51004) located at $\left(17.586^{\circ} \mathrm{N}, 152.461^{\circ} \mathrm{W}\right)$. This dataset will be used to evaluate the predicted $24-\mathrm{hr}$ wind speed and wind direction over the nearby ocean of Hawaii under the influence of different weather systems and events. The evaluations will be presented in section 4 .

\subsection{Methodology}

\subsubsection{The ARW and the Associated 3D-Var System}

To study the impact of QuikSCAT winds on the lowlevel wind field in its initial condition and the associated numerical predictions in the near-ocean surface winds around Hawaii, the Advanced Research WRF (ARW) mesoscale model (Skamarock et al. 2008) and WRF 3D-Var system

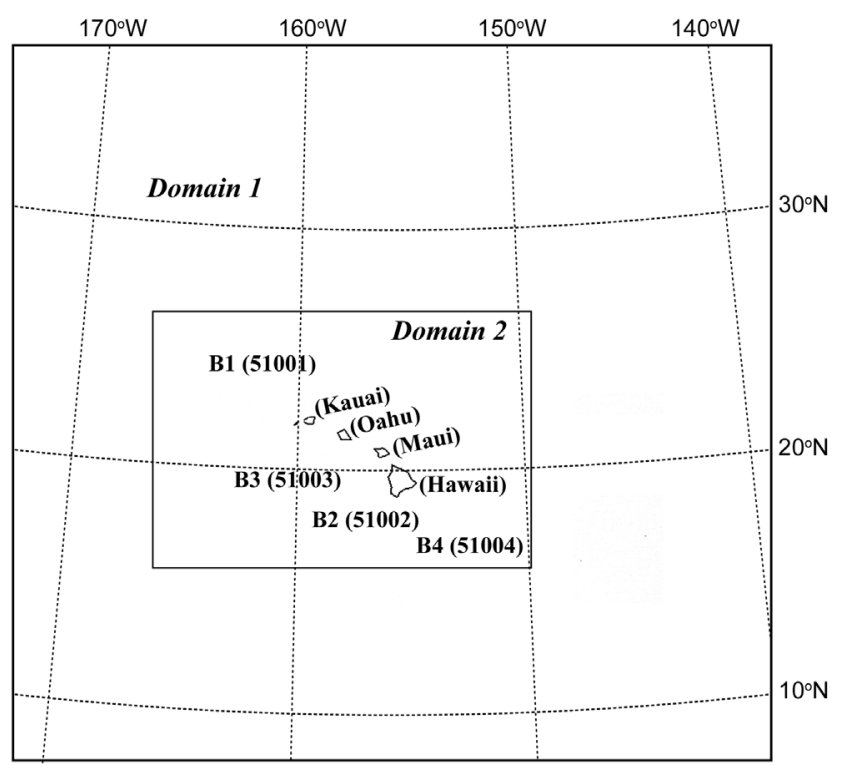

Fig. 2. Model domains with 18- and 6-km horizontal resolution for the course domain and nested domain. Four buoy sites belong to the National Data Buoy Center (NDBC) are presented by B1(51001), B2(51002), B3(51003), and B4(51004). 
which is developed from MM5 3D-Var (Barker et al. 2004) and used in many WRF data assimilations (e.g., Xiao and Sun 2006; Xiao et al. 2009) was used.

In the vertical, the ARW model have thirty-eight sigma levels from the surface $(\sigma=1.0)$ to $50 \mathrm{hPa}(\sigma=0.0)$ used in the model domains (Fig. 2). A fine domain with the 6-km grid-spacing is nested within a coarse domain with the $18-\mathrm{km}$ grid spacing. The ARW model physics include planetary boundary layer (PBL) processes using the Yonsei University scheme (Skamarock et al. 2005), short-wave radiation (Dudhia 1989) and long-wave radiation (Mlawer et al. 1997), land surface physics (Chen and Dudhia 2001), and precipitation physics. The precipitation is calculated by both the explicit scheme using mixed-phase processes (Ferrier et al. 2002) and implicit scheme using the Betts-MillerJanjić scheme (Janjić 1994, 2000) for the coarse domain and the nested domain.

To produce the optimal initial conditions for the numerical simulation, the WRF 3D-Var system is used to assimilate QuikSCAT winds. The 3D-Var system determines the analysis vector $\mathbf{x}$ by minimizing the cost function $J(\mathbf{x})$, defined as

$$
J(\mathbf{x})=1 / 2\left(\mathbf{x}-\mathbf{x}^{\mathrm{b}}\right)^{\mathrm{T}} \mathbf{B}^{-1}\left(\mathbf{x}-\mathbf{x}^{\mathrm{b}}\right)+1 / 2\left(\mathbf{y}-\mathbf{y}^{\mathrm{o}}\right)^{\mathrm{T}}(\mathbf{E}+\mathbf{F})^{-1}\left(\mathbf{y}-\mathbf{y}^{\mathbf{o}}\right)
$$

In Eq. (1), the analysis vector, $\mathbf{x}$, consists of the model variables, wind components, temperature, pressure perturbation, and mixing ratio of water vapor, all at the model levels. The vector $\mathbf{x}^{\mathbf{b}}$ is the background information first guess, which is taken from the global Forecasting system (GFS) or NCEPFNL reanalyses; $\mathbf{B}$ is the background error covariance matrix, which was derived from one-month WRF forecasts data with the NMC-method (Parrish and Derber 1992); $\mathbf{y}^{\mathbf{0}}$ is the observation vector and $\mathbf{y}$ is the equivalence of the observations transformed from the analysis vector $\mathbf{y}=\mathrm{Hx} ; \mathbf{E}$ and $\mathbf{F}$ are the observation (instrumental) and representative error covariance matrices, respectively. The representative error is an estimate of inaccuracies introduced in the observation operator $\mathrm{H}$.

In addition, the WRF 3D-Var system uses an incremental approach. With certain dynamic/physics constraints, such as hydrostatic assumption, cyclostrophic/geostrophic balance, etc., the control variables in this system are the increments of the stream function, potential velocity, unbalanced pressure, and mixing ratio/relative humidity. The analysis from the 3D-Var system can be an optimal combination of the observation information $\left(\mathbf{y}^{\mathbf{o}}\right)$, prior statistics $(\mathbf{B}, \mathbf{E}, \mathbf{F})$, and the dynamics/physics. As will be shown in section 4 , the assimilation of the reanalyzed ocean surface winds produced increments in the wind field through the dynamical/physical constraints.

It is, however, difficult to accurately define the error covariance matrices; therefore, the quality of the output analysis will be crucially dependent on the accuracy of these error statistics.

\subsubsection{Low-Pass Objective Analysis and Statistical Method}

The low-pass objective analysis (Maddox 1980) in Eqs. (2), (3), and (4) is conducted to fill out blank areas of QuikSCAT winds during ascending and descending time through the daily map as the lack of the data over the Hawaiian Island chains completely.

$$
\begin{aligned}
& \mathrm{f}(\mathrm{i}, \mathrm{j})=\mathrm{f}_{\mathrm{o}}(\mathrm{i}, \mathrm{j})+\sum_{\mathrm{n}=1}^{\mathrm{N}} w_{n}^{\prime} D_{n} / \sum_{\mathrm{n}=1}^{\mathrm{N}} W_{n}^{\prime} \\
& D_{n}=\mathrm{f}_{\mathrm{n}}(\mathrm{i}, \mathrm{j})-\mathrm{f}_{\mathrm{o}}(\mathrm{i}, \mathrm{j}) \\
& W_{n}^{\prime}=\exp \left(-d_{n}^{2} / 4 g c\right), \quad 0<g<1
\end{aligned}
$$

where $f(i, j)$ and $f_{o}(i, j)$ are the final grid value and first guess at grid point $(i, j)$, respectively. Here, the daily map of the satellite-derived ocean surface wind serves as the first guess; $D_{n}$ is the difference between an observed data value and the first estimate value at the same point. A simple bi-quadratic interpolation between the values of $f_{o}(i, j)$ at the four nearest grid points is used to estimate $\mathrm{f}_{0}(\mathrm{i}, \mathrm{j}) ; W_{n}^{\prime}$ is the modified weight function; $d_{n}$ denotes the distance from the $(i, \mathrm{j})$ grid point to the location of the observed data $\mathrm{f}_{\mathrm{n}}(\mathrm{x}, \mathrm{y}) ; c$ and $g$ are the weighting function constants (Maddox 1980). After the low-pass analysis of QuikSCAT winds, the reanalysis data and final values in Eq. (2) can be used to analyze the propagation of a surface cold front over the open ocean, as will be described in section 3 .

Furthermore, the statistical method, mean squared error (MSE)(Wilks 2006) shown in Eq. (5), is computed to simply evaluate the performance in the predicted near-ocean surface winds around Hawaii.

$\mathrm{MSE}=\frac{\sum_{i=1}^{N}\left(F_{i}-O_{i}\right)^{2}}{N}$

In Eq. (5), $F_{i}$ and $O_{i}$ refer to forecast and observed nearocean surface wind speed/direction from the buoy observations, respectively, for the time $i$ respectively, and the summation is over the number point $N$. Here, $N$ is equal to 24 for the predicted 24-hr period with a 1-hr time interval. Due to the squaring function in MSE, it will be more sensitive to larger errors. Clearly the MSE for a perfectly forecast field is zero, with larger MSE indicating decreasing accuracy of the forecast (Wilks 2006). 
The average of the MSE in the predicted 10-m winds, based on four different weather systems, is exploited to reveal the impact on the short-term forecast of near-ocean surface winds by assimilated QuikSCAT wind data. The valid time slot in the forecast of the 24-hr near-ocean surface winds under different weather conditions is 0000 UTC 5 April - 0000 UTC 6 April 2008 (Kona storm), 0000 UTC 11 April - 0000 UTC 12 April 2008 (cold front), 0000 UTC 13 February - 0000 UTC 14 February 2001 (strong wind), and 0000 UTC 8 May - 0000 UTC 9 May 2008 (trade wind), respectively.

\section{DETECTION OF THE WEATHER SYSTEMS OVER THE OPEN OCEAN BY QUIKSCAT WINDS}

Using QuikSCAT wind data, the detection of the weather systems over the open ocean around Hawaii is analyzed. Four frequent weather systems and events in Hawaii are examined, including a Kona storm (5 April 2008), a surface cold front (11 April 2008), the strong anticyclone with a high-wind event (13 February 2001), and a trade-wind condition (08 May 2008). The first three episodes are potentially hazardous weather systems during the winter (cool) season (November - April) in Hawaii. Trade-wind conditions are the most prevalent during the Hawaii summer time under the influence of subtropical high pressure.

During the winter in Hawaii, Kona storms are notorious producers of heavy rain, strong winds, and the high surf. As pointed out by Kodama and Businger (1998), the erratic movement and persistence of these systems, both relatively poorly forecasted by the operational global forecast models, present a considerable challenge to predict the onset and cessation of the attendant hazardous weather conditions. At 0000 UTC on 5 April 2008, the surface weather map, subjectively analyzed by the National Weather Service (NWS) Honolulu Weather Forecasting Office (WFO), shows that a Kona low over northeast of Hawaii (Fig. 3a) after it separated from an occluded frontal system (not shown) as revealed by Simpson (1952). A high-pressure center is located at the northwest of the Kona storm north of Islands. Compared with the surface weather map, QuikSCAT winds at the descending time (0200 - 0400 UTC) on 5 April 2008 reveal a significant cyclonic circulation (Fig. 3b) consistent with a low-pressure system (Fig. 3a). Apparent wind speeds greater than $10 \mathrm{~m} \mathrm{~s}^{-1}$ are shown over the open ocean around the Kona low. Meanwhile, an anticyclonic circulation pattern (Fig. 3b) associated with a high-pressure system (Fig. 3a) located over the northwest of the Kona low, is also revealed from the retrieved oceanic winds, although there is a swath gap passing through the center of the anticyclonic circulation.

For the winter cold frontal system in the Hawaiian Islands, an average of nine cold fronts per year with sufficient strength can pass through the entire island chain (Kodama and Businger 1998). Due to modifying effects of the surrounding ocean, the changes in temperature with the passage of a surface front are minor compared to those in midlatitudes, but change is locally perceived (Schroeder 1993). Frequently, frontolysis occurs prior to the front reaching the (a)

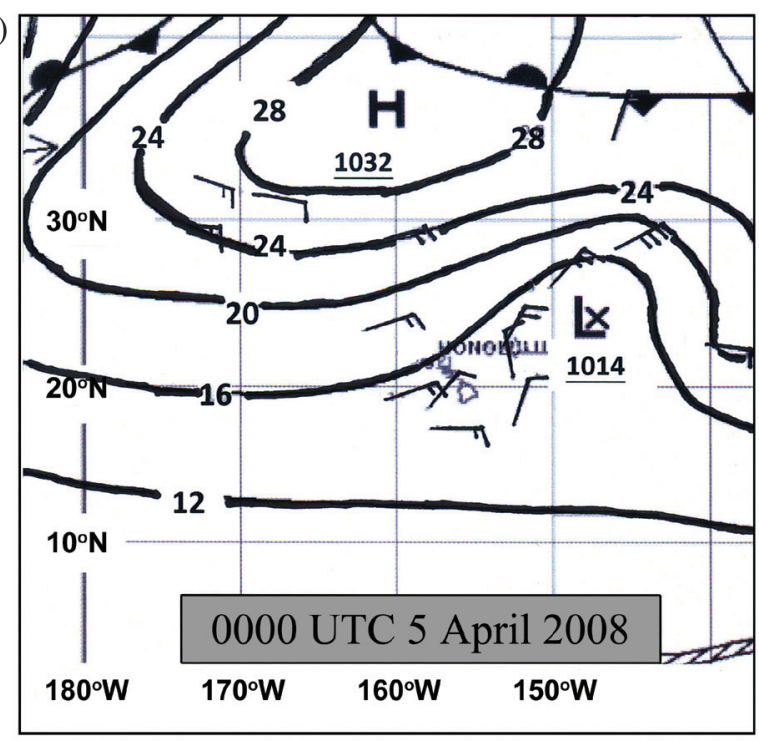

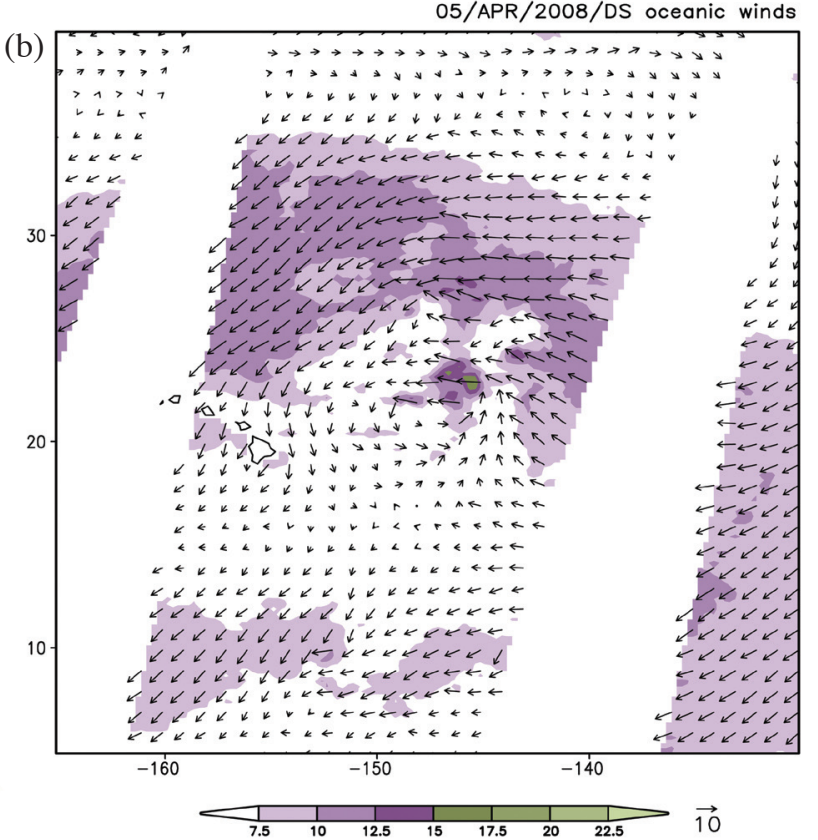

Fig. 3. (a) Surface weather analysis by National Weather Service (NWS), Honolulu Weather Forecasting Office (WFO) at 0000 UTC on 5 April 2008, and (b) The QuikSCAT winds at 0200 - 0400 UTC on 5 April 2008. The wind speed (shaded) starts from $5 \mathrm{~m} \mathrm{~s}^{-1}$ with a $2.5 \mathrm{~m} \mathrm{~s}^{-1}$ interval. 
Hawaiian Islands, so that the only obvious feature for the approaching surface cold front is a wind discontinuity with cyclonic shear on its poleward side (Kodama and Businger 1998). However, the low-level conventional observations are insufficient over the open ocean and it has been difficult to determine the location of the surface frontal boundary on the basis of a wind discontinuity. With the availability of QuikSCAT winds, to determine the location of the surface frontal boundary over the open ocean becomes possible. At 0000 UTC on 11 April 2008, the surface weather map shows a surface front (Fig. 4a) over the open ocean that later will move through the Hawaii area. The QuikSCAT winds clearly reveal a frontal boundary (Fig. 4b) where the wind shift and wind confluence are significant. The anticyclonic circulation in the prefrontal and postfrontal regions (Fig. 4b) also coincides with the high-pressure systems shown on the surface map (Fig. 4a).

In addition, the propagation of the surface cold front also can be analyzed through the time series of the reanalyzed oceanic winds reproduced by low-pass objective analysis as introduced in section 2.2. In Fig. 5, the reanalyzed oceanic winds are used to identify the surface frontal boundary and to reveal the propagation of the surface cold front over the ocean north of Hawaii during 11 - 12 April 2008. At the descending time (0200 - 0400 UTC) 11 April, a distorted surface frontal boundary is determined by the wind shift and wind confluence (Fig. 5a), which is slightly ahead of the surface front subjectively analyzed in the surface weather map (Fig. 4a). In the postfrontal regions, the strong northwesterly flow (Fig. 5a) has a maximum of
$15-17.5 \mathrm{~m} \mathrm{~s}^{-1}$. At the ascending time (1300 - 1700 UTC) 11 April, the southern portion of the frontal boundary moves eastward and affects the Hawaii area (Fig. 5b). Meanwhile, strong winds occur in the postfrontal regions and the wind speeds in the surrounding ocean of Hawaii also increase significantly. The frontal boundary moves eastward over the ocean at the descending time of 12 April (Fig. 5c) and the wind increases in the Hawaiian Island chain, especially on land and over the nearby ocean north of Hawaii. The surface front subsequently moves outside the analyzed domain and dissipates.

Under the influence of synoptic scale forcing (subtropical Kona storm and extratropical cold frontal system) and complex island topography, localized strong winds frequently occur over Hawaii during the winter (cool) season (Schroeder 1977). Sometimes, strong northeasterly winds dominate in Hawaii as the postfrontal high pressure system merges with the semi-permanent subtropical high and strengthens with a center just to the north of Hawaiian Islands (Schroeder 1993). As studied by Zhang et al. (2005), a strengthening high pressure system located just to the north of the Hawaiian Islands produced a strong wind episode during 14 - 15 February 2001. In this event, strong winds are in excess of $15 \mathrm{~m} \mathrm{~s}^{-1}$ with gusts greater than $22 \mathrm{~m} \mathrm{~s}^{-1}$ across the state, with trees knocked down and power disrupted in many communities (Zhang et al. 2005). With the help of the reanalyzed oceanic winds, the stronger wind speed $\left(>10 \mathrm{~m} \mathrm{~s}^{-1}\right)$ can be detected over the islands of Oahu and Kauai (Fig. 6b) and the nearby ocean with a maximum in excess of $12.5 \mathrm{~m} \mathrm{~s}^{-1}$ one day before the strong winds im- (a)

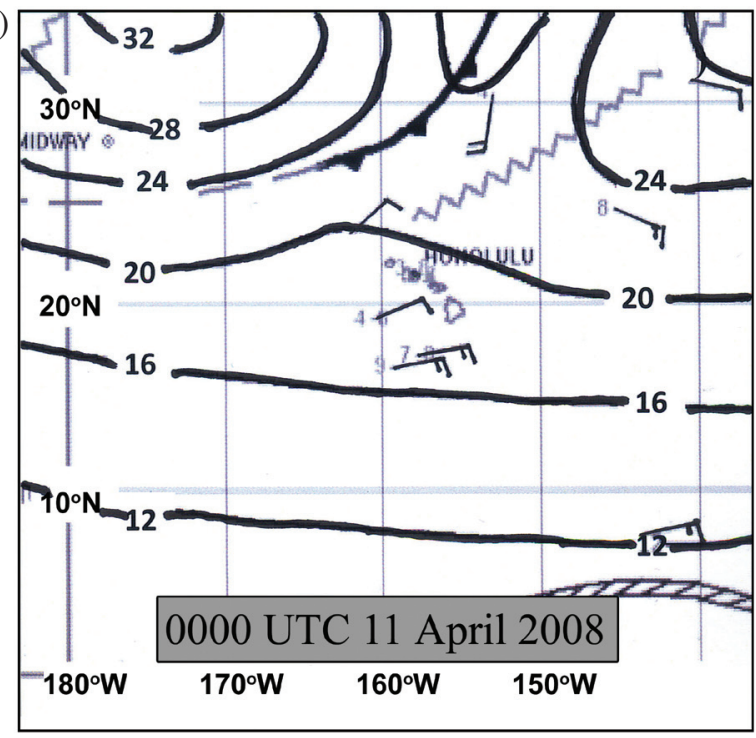

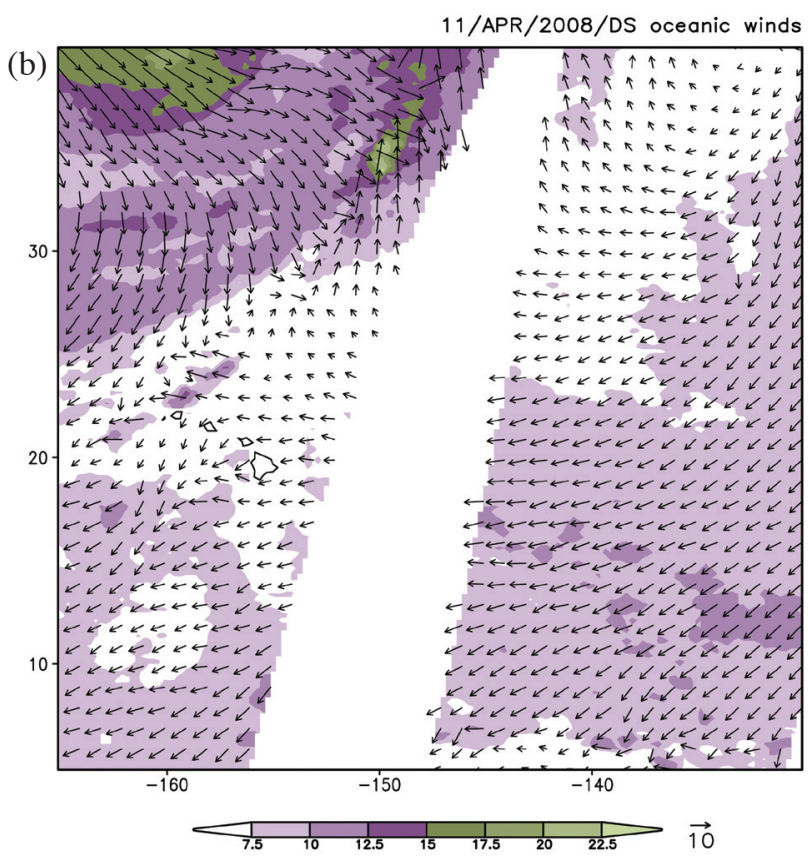

Fig. 4. Same as Fig. 3 but for 11 April 2008. 
pact the islands. The anticyclonic circulation $\left(30-40^{\circ} \mathrm{N}\right.$, $\left.170-155^{\circ} \mathrm{W}\right)($ Fig. $6 \mathrm{~b})$ is consistent with the location of a high-pressure system as analyzed by NWS Honolulu WFO (Fig. 6a). Ahead of the high pressure, the surface front boundary with a wind shift and wind confluence (Fig. 6b) is significant and coincides with surface front analysis on the surface weather map (Fig. 6a).

After the winter (cool) season in Hawaii, the subtropical high dominates over the Pacific Ocean in the northern Hemisphere and the northeasterly low-level winds prevailing over the tropical Pacific are known as trade winds (Schroeder 1993). Over the Hawaiian Islands, the trade winds are observed $70 \%$ of the year and around $90 \%$ of the days during the summer, subsequently decreasing to around $50 \%$ during the winter season (Schroeder 1993) with the
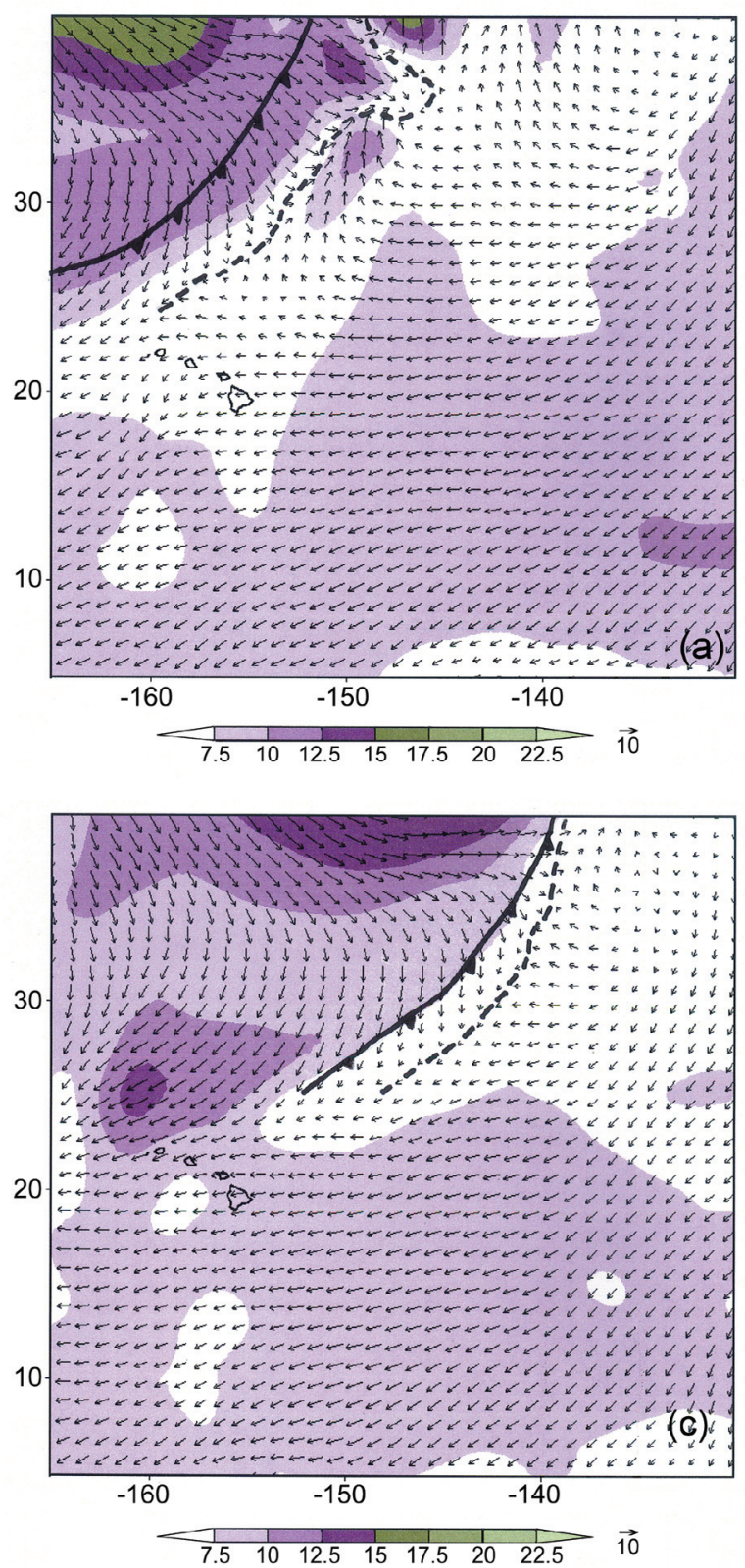

migration and evolution of the subtropical high. For a trade-wind day on 8 May 2008, QuikSCAT winds reveal an anticyclonic circulation (Fig. 7b) over the open ocean northeast of the Hawaiian Islands, which is associated with the subtropical high pressure (Fig. 7a). The northeasterly-to-easterly flow prevails through the Hawaiian Island chain.

On the basis of studies in frequent weather systems and events around Hawaii, QuikSCAT winds and the reanalyzed oceanic winds in the surrounding ocean of Hawaii can clearly detect the circulation and the movement of the associated weather systems over the open ocean. The evaluation of their impact on the prediction of the near-ocean surface winds through the incorporation of the reanalyzed oceanic winds is presented in section 4 .

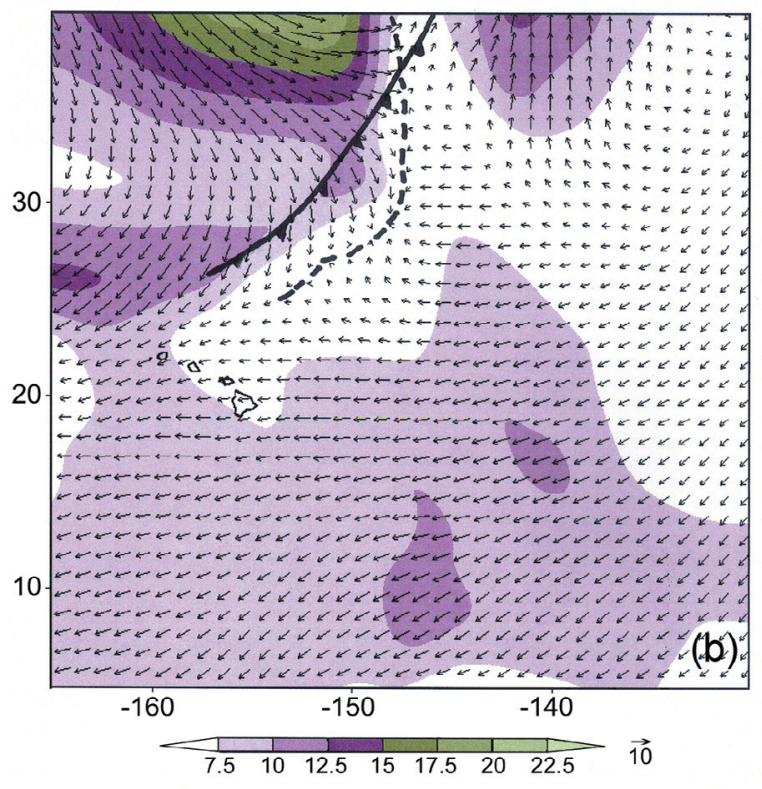

Fig. 5. The reanalyzed ocean surface winds at (a) 0200 - 0400 UTC on 11 April 2008, (b) 1300 - 1700 UTC on 11 April 2008, and (c) 0200 - 0400 UTC on 12 April 2008. The surface front analyzed by NWS Honolulu WFO is presented using the solid line. The surface frontal boundary analyzed by the reanalyzed QuikSCAT winds is represented by the dashed line. The wind speed (shaded) starts from $5 \mathrm{~m} \mathrm{~s}^{-1}$ with a $2.5 \mathrm{~m} \mathrm{~s}^{-1}$ interval. 
(a)

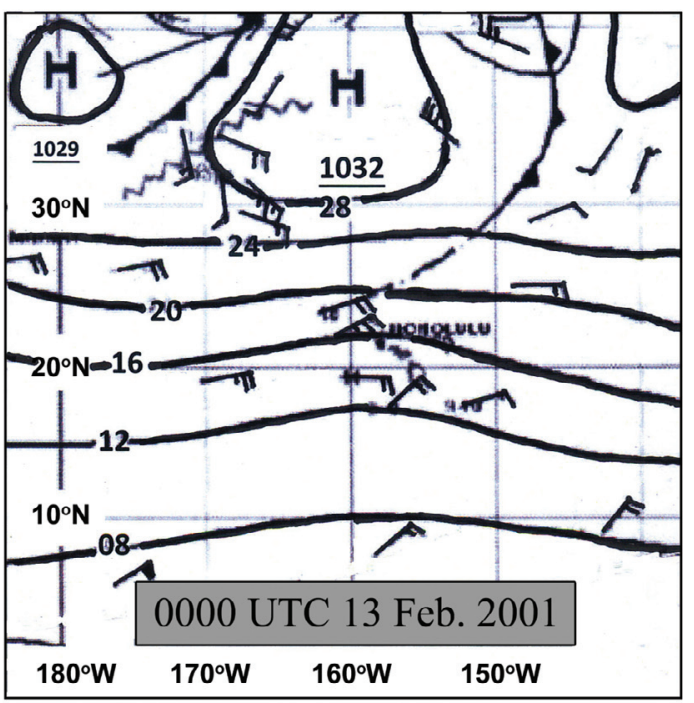

$13 / \mathrm{Feb} / 2001 / \mathrm{DS}-\mathrm{N}$ oceanic winds

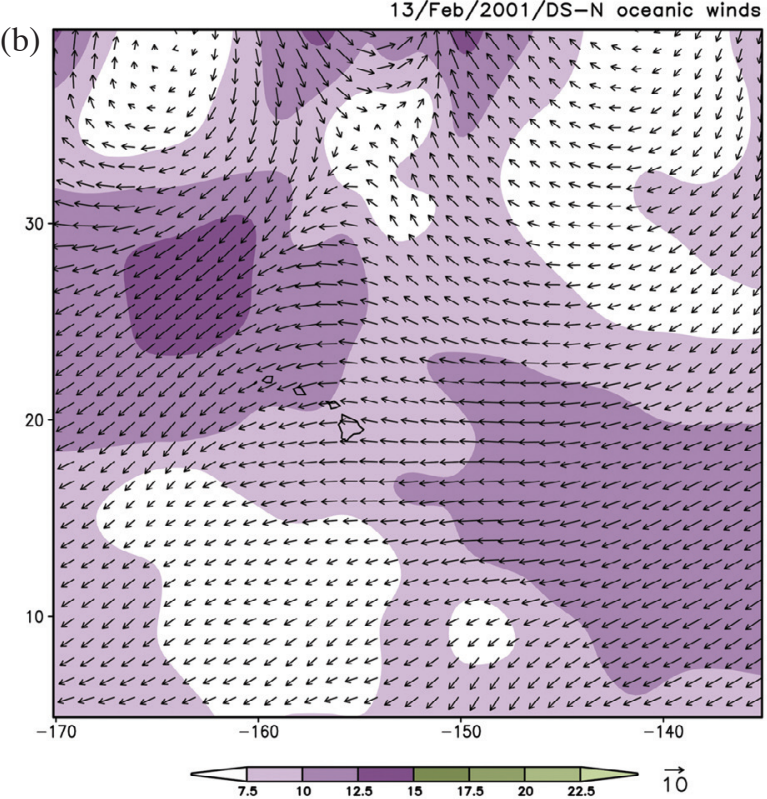

Fig. 6. (a) Surface weather analysis by National Weather Service (NWS), Honolulu Weather Forecasting Office (WFO) at 0000 UTC on 13 February 2001, and (b) The reanalyzed QuikSCAT winds at 0200 - 0400 UTC on 13 February 2001. The wind speed (shaded) starts from 5 m s${ }^{-1}$ with a $2.5 \mathrm{~m} \mathrm{~s}^{-1}$ interval.

(a)

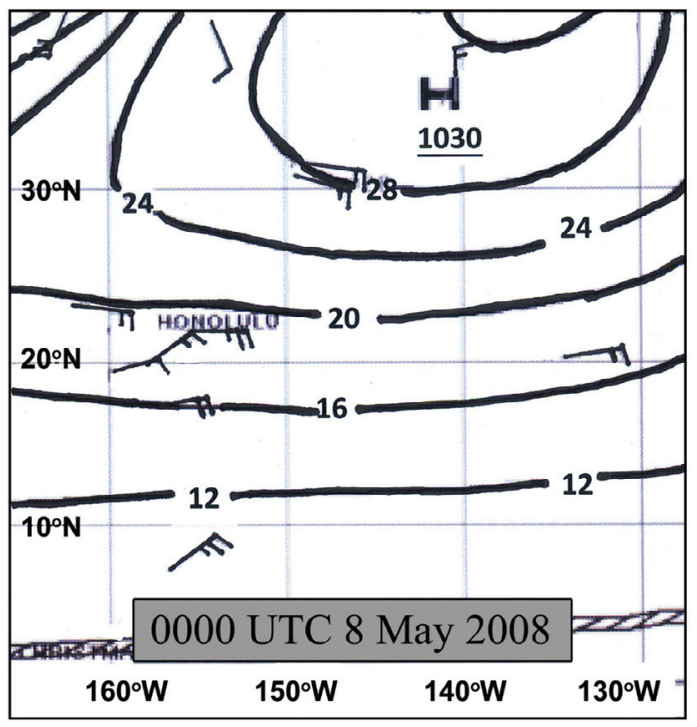

$08 /$ May/2008/DS oceanic winds

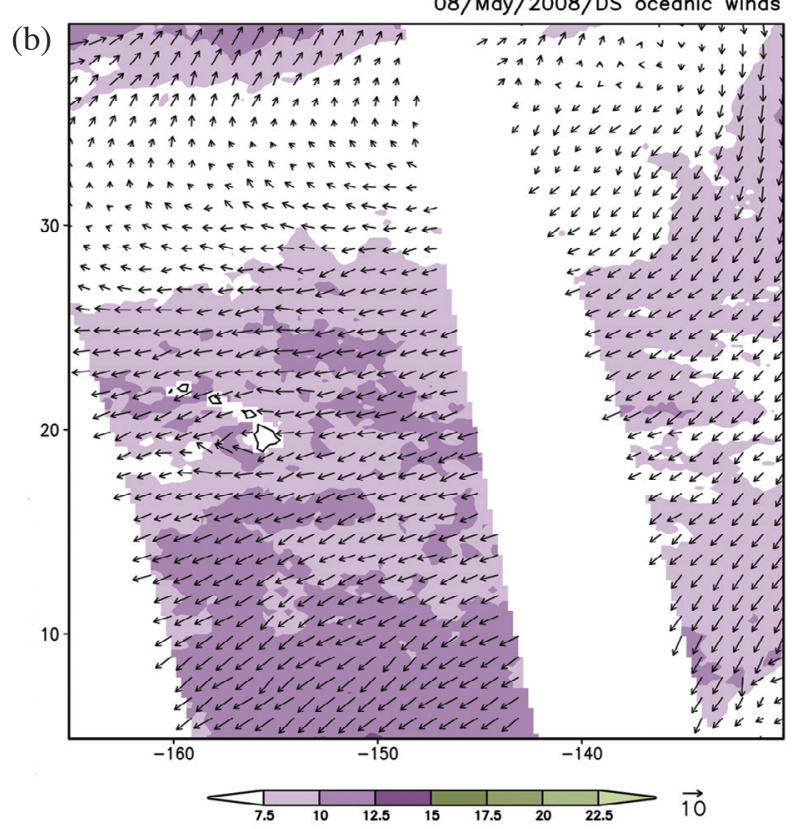

Fig. 7. Same as Fig. 3 but for 8 May 2008.

\section{IMPACT ON NEAR-OCEAN SURFACE WIND AND THE ASSOCIATED SHORT-TERM FORE- CAST WITH ASSIMILATED QUIKSCAT WINDS}

Using the reanalyzed oceanic winds from the WRF 3D-Var system, the improvement in the 24-hr forecast of near-ocean surface winds under different weather conditions can be seen and is discussed in section 3 .
For a Kona storm at 0000 UTC on 5 April 2008, the low-level winds at the 1000 -hPa level (Fig. 8a) with assimilated QuikSCAT winds obviously increase the northerly wind component over the Hawaiian islands and the nearby ocean, as compared with the global forecasting system (GFS) analysis (Fig. 8b). The difference in the wind speed of the initial $1000-\mathrm{hPa}$ winds reveals that a maxima 
center $\left(>4 \mathrm{~m} \mathrm{~s}^{-1}\right)$ occurs over the nearby ocean, just south of Oahu (Fig. 8c). Outside the Hawaiian Island chain, the impact of the assimilated oceanic wind is reduced over the ocean. In the vertical, the impact of the low-level winds extends to the 750-hPa level (not shown). At 0000 UTC 6 April 2008, the 24-hr low-level wind prediction at the 1000$\mathrm{hPa}$ level strengthen over the Hawaii Island chain and the nearby ocean with assimilated QuikSCAT winds (Fig. 9a) as the deepening of the Kona storm over the northeast of Hawaii. Due to the effects of Island obstacle, the predicted near-ocean surface winds among the Hawaiian Islands are stronger with assimilated QuikSCAT winds than those in the GFS run (Fig. 9b) and QuikSCAT winds (Fig. 9c). To the nearby ocean south of Hawaiian Island, the increase of near-ocean surface winds are associated with the weak hydraulic jump (Smith and Grubišić 1993), which is not revealed by the global analysis and QuikSCAT winds under the coarse spatial resolution.
For a surface cold front at 0000 UTC on 11 April 2008, the easterly and northeasterly winds at the $1000-\mathrm{hPa}$ level increase in the surrounding ocean of Hawaii with the assimilated oceanic winds (Fig. 10a) as compared with the GFS run (Fig. 10b). The difference in the wind speed of the initial $1000-\mathrm{hPa}$ winds reveals that the maxima in wind speed difference greater than $4 \mathrm{~m} \mathrm{~s}^{-1}$ occurs over the nearby ocean, north of Oahu (Fig. 10c). The significant impact regime by the assimilated oceanic winds extended northwestward along the Hawaiian Island chain where a cold front is approaching (Fig. 4). For the 24-hr low-level wind prediction at the $1000-\mathrm{hPa}$ level, the postfrontal northeasterly winds increase significantly with assimilated oceanic winds (Fig. 11a) and the GFS run (Fig. 11b), consistent with QuikSCAT winds (Fig. 11c). The numerical predictions also reproduce the channel winds among the Hawaii Islands chain. In addition, the approaching northeasterly winds over the Island of Hawaii are obviously decelerated and split by (a)

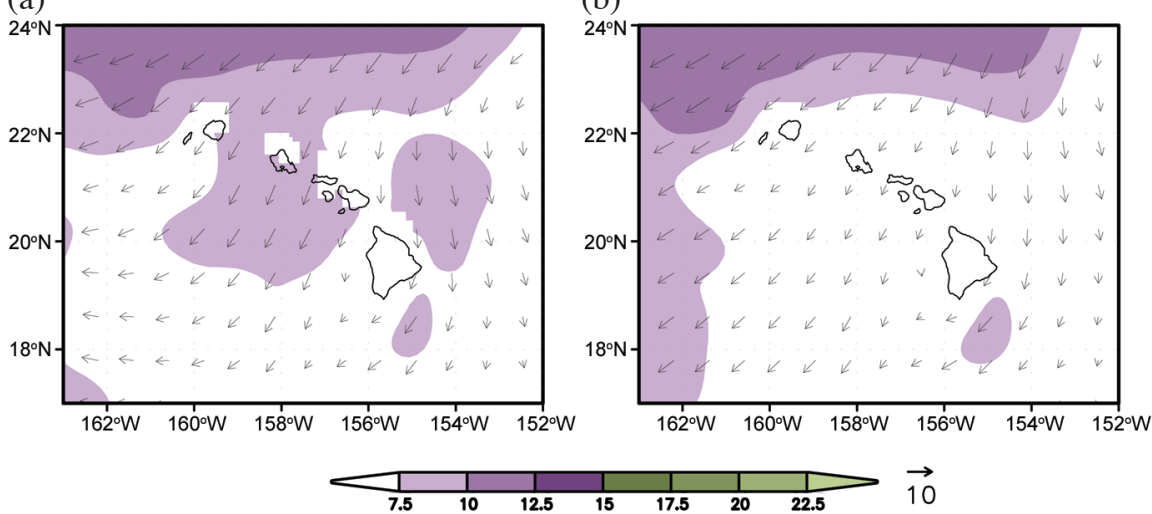

(c)

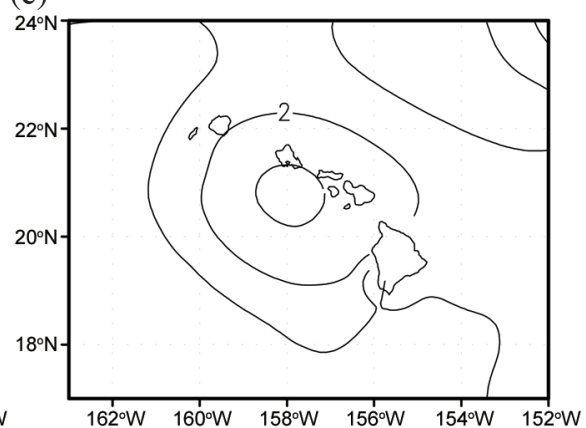

Fig. 8. (a) Initial 1000-hPa wind vector and wind speed (shaded) with the assimilated QuikSCAT winds, (b) Initial 1000-hPa wind vector and wind speed (shaded) for the GFS run, and (c) The contour of wind speed difference between (a) and (b) with a $2 \mathrm{~m} \mathrm{~s}^{-1}$ interval, at 0000 UTC on 5 April 2008. The shaded in (a) and (b) starts from $5 \mathrm{~m} \mathrm{~s}^{-1}$ with a $2.5 \mathrm{~m} \mathrm{~s}^{-1}$ interval.

(a)

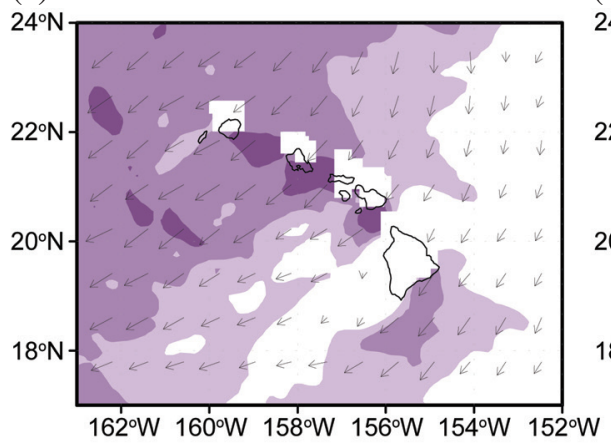

(b)

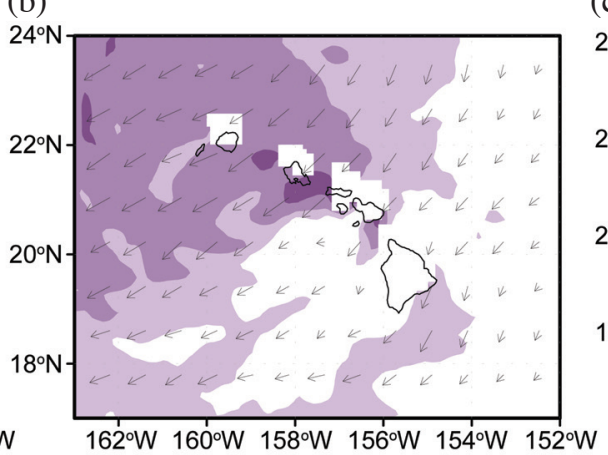

(c) $06 / \mathrm{APR} / 2008 / \mathrm{DS}-\mathrm{s}$ oceanic winds

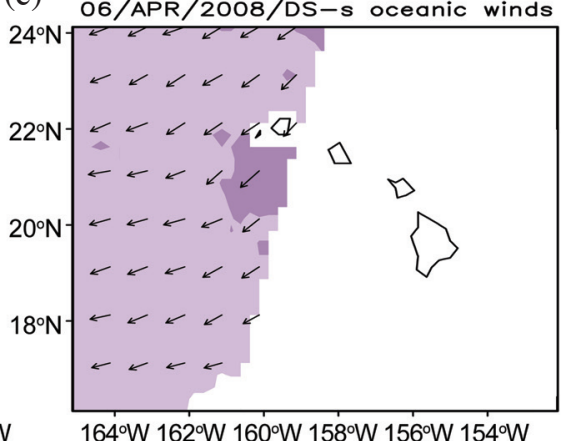

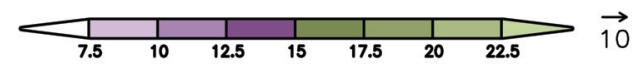

Fig. 9. (a) Simulated 1000-hPa wind vector and wind speed (shaded) with the assimilated QuikSCAT winds, (b) Simulated 1000-hPa wind vector and wind speed (shaded) for the GFS run at 0000 UTC on 6 April 2008, and (c) The QuikSCAT wind field, at 0200 - 0400 UTC on 6 April 2008. The shaded in (a), (b), and (c) from $5 \mathrm{~m} \mathrm{~s}^{-1}$ with a $2.5 \mathrm{~m} \mathrm{~s}^{-1}$ interval. 
(a)

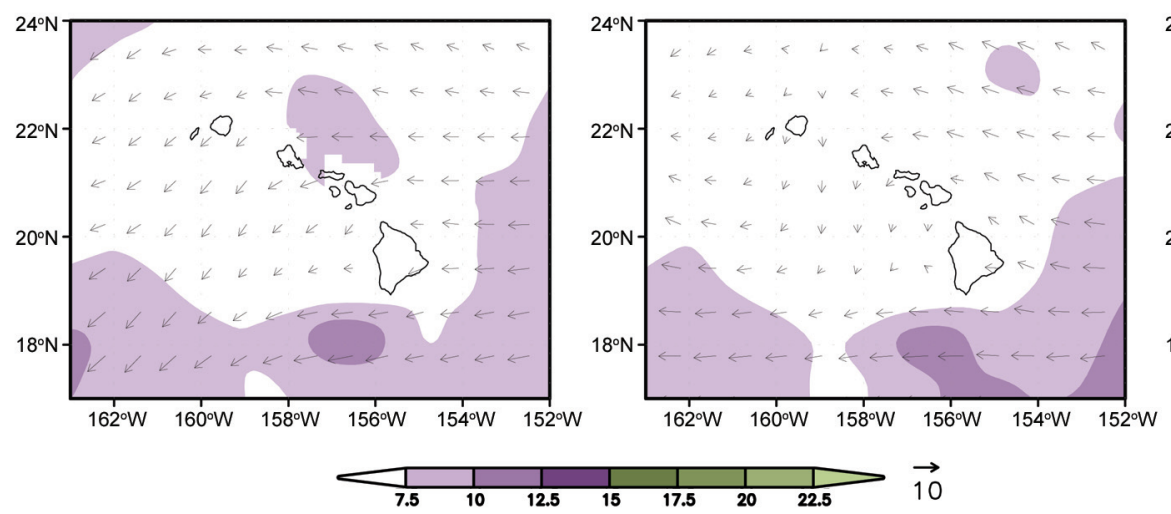

Fig. 10. Same as Fig. 8 but for 11 April 2008. (c)

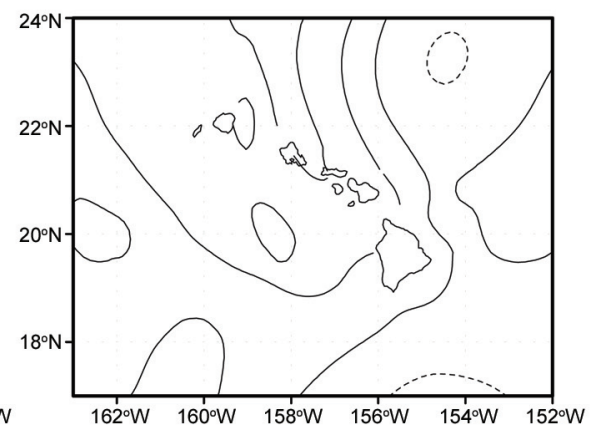

(a)

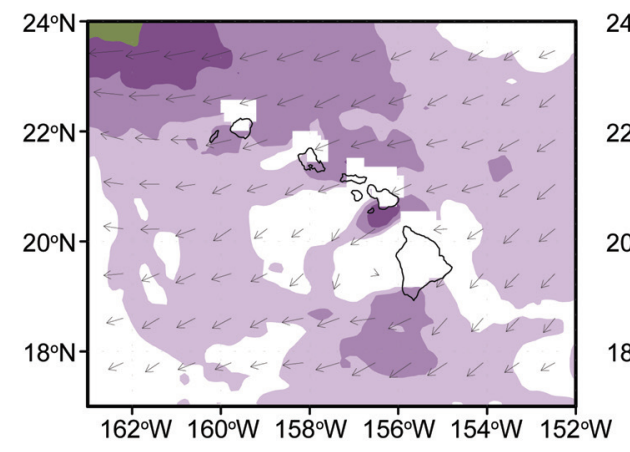

(b)
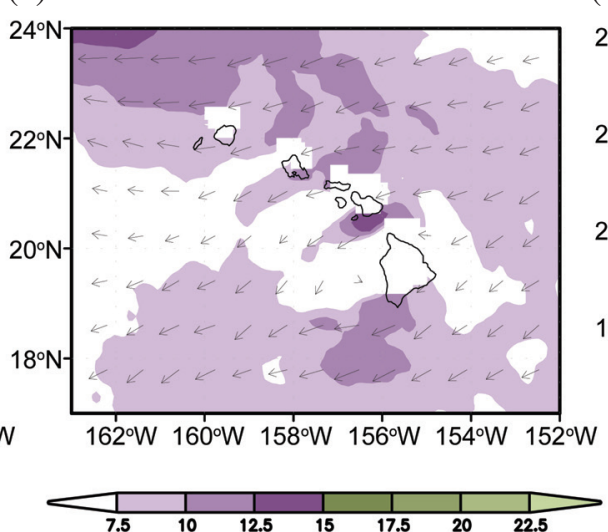

(c)

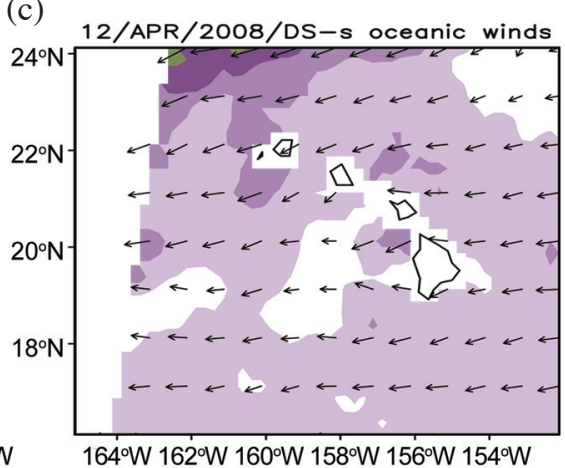

$\overrightarrow{10}$

Fig. 11. Same as Fig. 9 but for 12 April 2008.

the Island obstacle in the windward side (Figs. 11a and b). Meanwhile, the Hawaii's wake in the leeside downstream is also simulated as revealed by Smolarkiewicz et al. (1988) and Smith and Grubišić (1993). Due to the relatively coarse horizontal resolution, the effects of the Island barrier to near-ocean surface winds are not resolved well in the satellite-derived QuikSCAT winds (Fig. 11c).

As studied by Zhang et al. (2005), a strong-wind case was produced over the Hawaiian Island chain because of the strengthening of a high pressure to the north of Hawaii during 14 - 15 February 2001. Recall that the sea level pressure gradient has increased (Fig. 6a) one day before the strong wind was observed over land in Hawaii. At 0000 UTC 13 February 2001, the assimilated oceanic winds in the model initial winds at the 1000-hPa level increase the wind speed (Fig. 12a) over the Hawaiian Island chain and over the open ocean in the downstream and to the north of Hawaii as compared with the initial 1000-hPa winds in the NCEP-FNL run (Fig. 12b). The wind direction at the same level turns to easterly in the windward side and becomes northeasterly in the downstream, consistent with the limited observations shown on the surface weather map (Fig. 6a). The difference in the initial 1000-hPa wind speed with assimilated oceanic winds from that in the NCEP-FNL run increases obviously and extends from southeast to the northwest through the Hawaiian Island chain (Fig. 12c), consistent with the increase of the sea-level pressure gradient there (Fig. 6a). The maximum difference in the wind speed at the $1000-\mathrm{hPa}$ level is greater than $8 \mathrm{~m} \mathrm{~s}^{-1}$. For the 24-hr 1000-hPa wind prediction, the significant enhancement of the northeasterly winds to the northwest of the Hawaii is reproduced (Figs. 13a and b), which is stronger than QuikSCAT winds (Fig. 13c). To the downstream ocean west of Hawaii, the predicted near-ocean surface winds with assimilated oceanic winds are stronger than those in the NCEP-FNL run. Orographic effects on near-ocean surface winds are also reproduced (Figs. 13a and $b$ ).

For a trade-wind day on 8 May 2008, the incorporation of the QuikSCAT winds in the model initial wind fields at the 1000-hPa level has increased the prevailing northeast- 
(a)

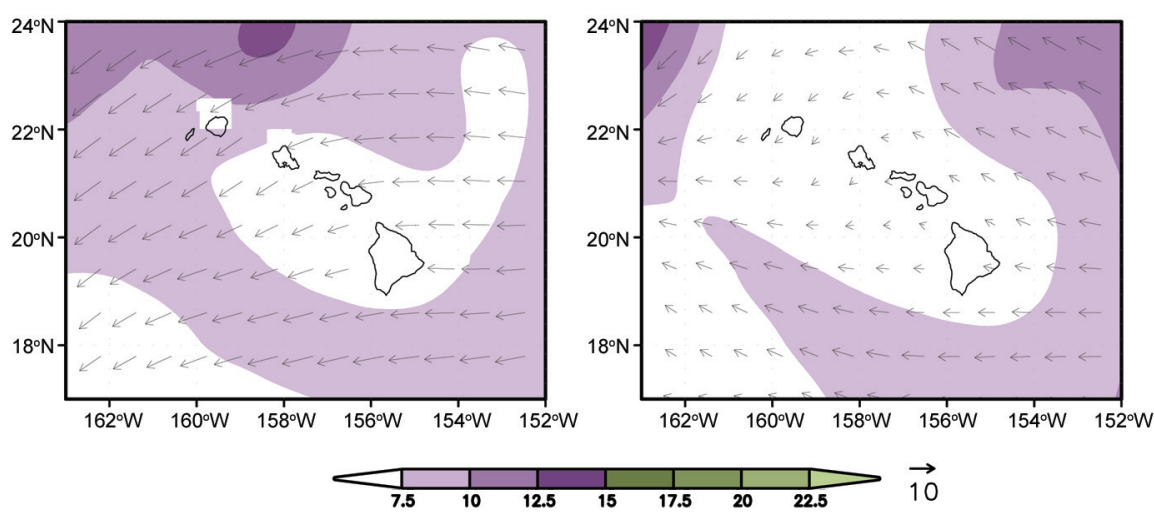

(c)

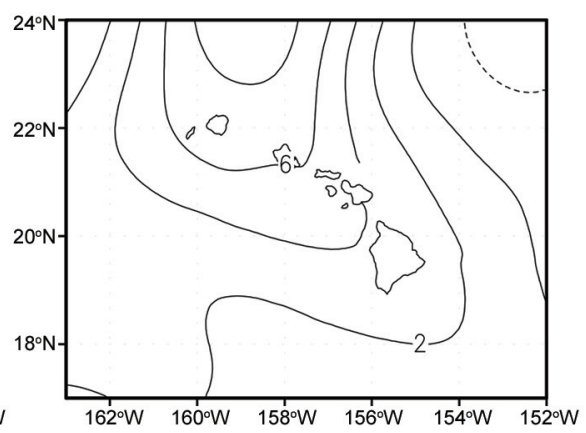

Fig. 12. (a) Initial 1000-hPa wind vector and wind speed (shaded) with the assimilated QuikSCAT winds, (b) Initial 1000-hPa wind vector and wind speed (shaded) for the NCEP-FNL run, and (c) The contour of wind speed difference between (a) and (b) with a $2 \mathrm{~m} \mathrm{~s}^{-1}$ interval, at 0000 UTC on 13 February 2001. The shaded in (a) and (b) starts from $5 \mathrm{~m} \mathrm{~s}^{-1}$ with a $2.5 \mathrm{~m} \mathrm{~s}^{-1}$ interval.

(a)

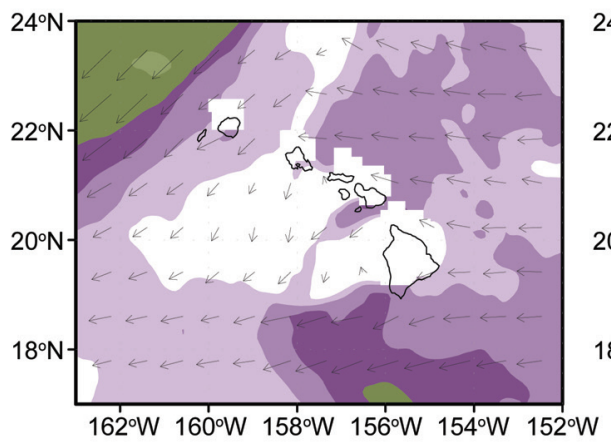

(b)

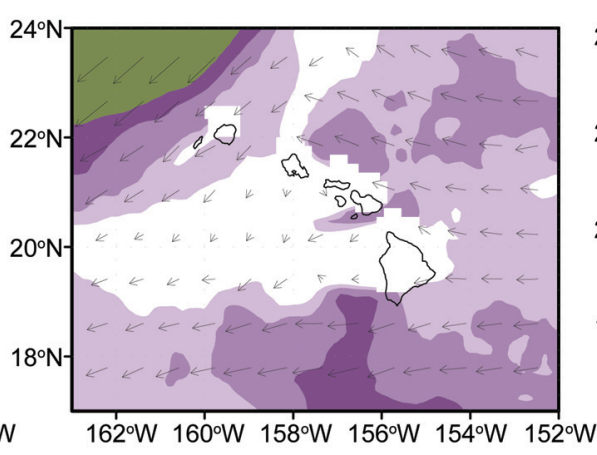

(c)

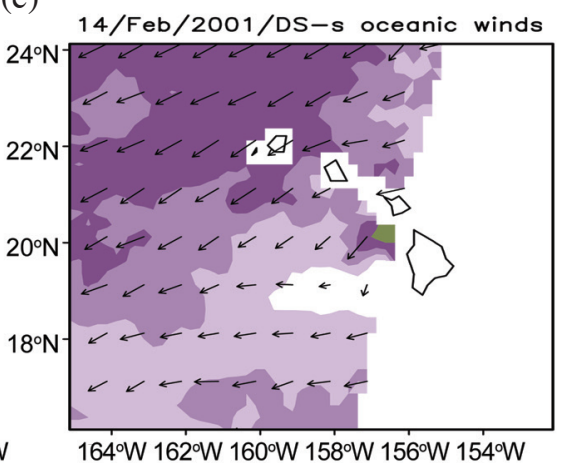

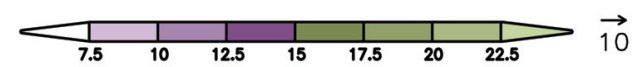

Fig. 13. (a) Simulated 1000-hPa wind vector and wind speed (shaded) with the assimilated QuikSCAT winds, (b) Simulated 1000-hPa wind vector and wind speed (shaded) for the NCEP-FNL run at 0000 UTC on 14 February 2001, and (c) The QuikSCAT wind field at 0200 - 0400 UTC on 14 February 2001. The shaded in (a), (b), and (c) starts from $5 \mathrm{~m} \mathrm{~s}^{-1}$ with a $2.5 \mathrm{~m} \mathrm{~s}^{-1}$ interval.

erly-to-easterly winds over the Hawaiian Island chain and in the downstream ocean of the Hawaiian Islands (Fig. 14a) compared with that in the GFS run (Fig. 14b). The significant difference in the $1000-\mathrm{hPa}$ wind speed $\left(>4 \mathrm{~m} \mathrm{~s}^{-1}\right)$ crosses the islands of Kauai and Oahu and extends westward to the downstream ocean (Fig. 14c). For the 24-hr 1000-hPa wind forecast, the predicted near-ocean surface winds (Figs. 15a and $b$ ) reproduce the prevailing easterly winds, consistent with QuikSCAT winds (Fig. 15c). Orographic effects on near-ocean surface winds are also revealed in the windward and the leeside ocean near the Island of Hawaii in the numerical weather predictions (Figs. 15a and b), which QuikSCAT winds (Fig. 15c) did not resolve well.

Note that the WRF 3D-Var system is performed on the terrain-following coordinate; orographic effects on the environmental airflow are triggered with the time integration of the numerical weather prediction. Without cycling, the impact of the assimilated QuikSCAT winds decreases significantly and reasonably after the 18 - to $24-\mathrm{hr}$ forecasting. To statistically evaluate the $24-\mathrm{hr}$ forecast of the $10-\mathrm{m}$ winds with 1-hr time intervals, the average of the MSE for four frequent weather systems and events in Hawaii (Fig. 16) are calculated through the discrepancy between four-buoy observations around the Hawaiian Island chain (Fig. 2) and the model forecasting, including the numerical weather predictions with assimilated QuikSCAT ocean surface winds and GFS/NCEP-FNL run.

For the impact on the 24-hr forecasting of the $10-\mathrm{m}$ winds (Fig. 16), the errors of wind speed and wind direction by the assimilated oceanic winds reduce around four buoys as compared with the GFS/NCEP-FNL run. Near buoy 1, the GFS run has significantly under-predicted the wind speed 
with more errors during the 24-hr forecasting (Fig. 17a) related to the passage of a surface cold front. Near buoys 2 and 3 , the errors for the $10-\mathrm{m}$ wind speed simulated with the assimilated oceanic winds decrease as compared with the wind speed errors predicted by the GFS/NCEP-FNL run, associated with the strong wind event in the downstream of the Hawaiian Island chain (Fig. 16). Here the NCEP-FNL predictions in the $10-\mathrm{m}$ wind speed for the strong wind event are apparently under-predicted near buoys 2 (not shown) and 3 (Fig. 17b) during the 24-hr forecasting. For the predicted 10-m wind direction, the statistical errors (Fig. 16b) with the assimilated oceanic winds are also reduced near the location of buoys 2 and 3. Near buoy 4, the predicted 10-m wind field with assimilated oceanic winds also has less statistical errors (Fig. 16).

\section{CONCLUSIONS}

With the help of QuikSCAT winds, the associated circulation of the weather systems over the open ocean around
Hawaii can be identified. In association with frequent weather systems and events around Hawaii, a significant cyclonic circulation related to a Kona low over the ocean northeast of Hawaii is detected by the QuikSCAT winds on 5 April 2008. It maintains the cyclonic circulation consistent with a low pressure over the ocean for several days. For the surface cold front, the paucity of the near-ocean surface wind observations and the weakening of the thermal contrast due to the modification of the surrounding ocean around Hawaii make it difficult to define the surface frontal boundary over the open ocean, even though the satellite imagery sometimes can help to determine the location of the surface cold front. The QuikSCAT winds provide not only the wind speed but also the wind direction, which is important and can be utilized to define the surface frontal boundary through the wind shift and wind confluence over the ocean. Therefore, the propagation of a cold front over the ocean north of Hawaiian Island chain can be detected using the reanalyzed oceanic winds during 11 - 12 April 2008.

In a strong-wind event one day after 13 February 2001, (a)

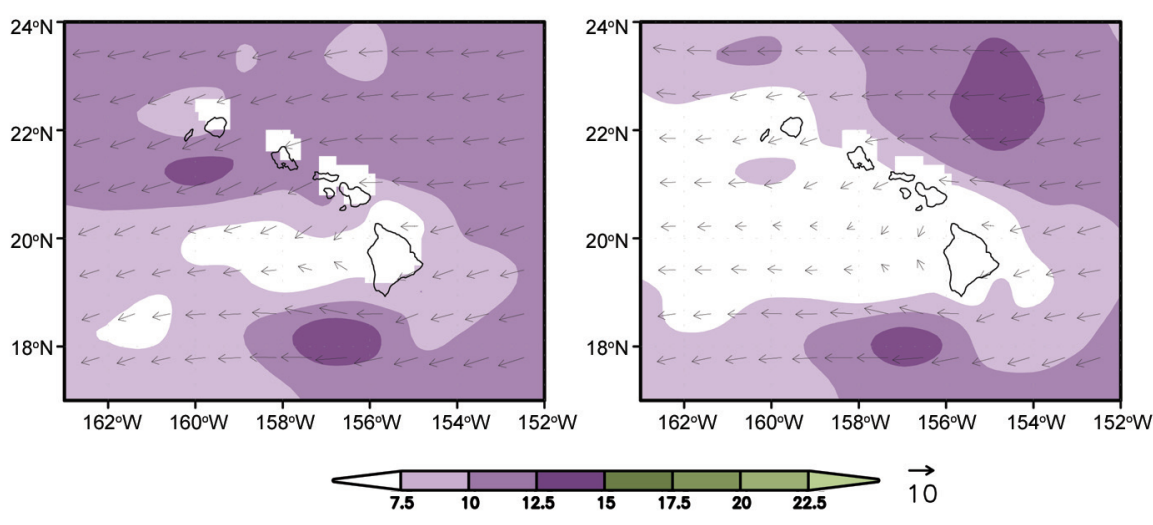

Fig. 14. Same as Fig. 8 but for 8 May 2008. (c)

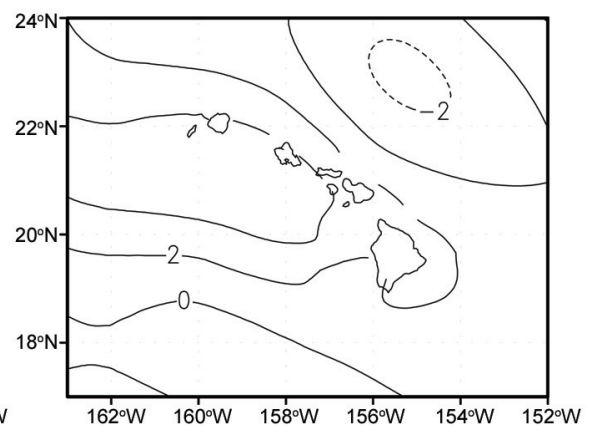

(a)

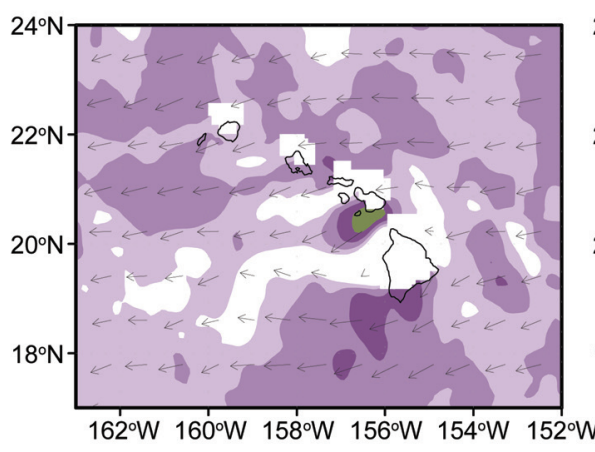

(b)
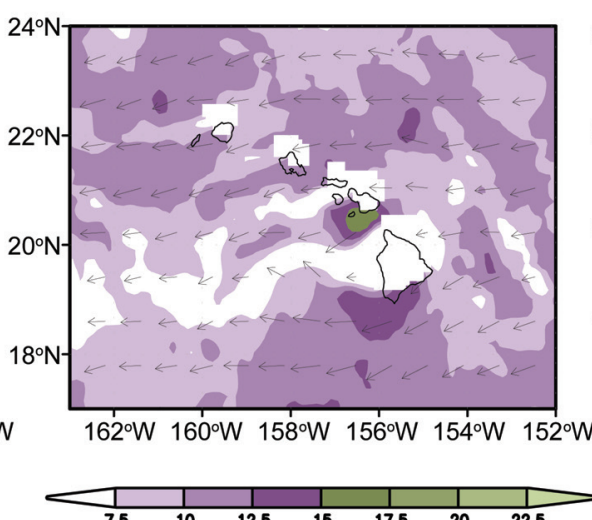

Fig. 15. Same as Fig. 9 but for 9 May 2008. (c)

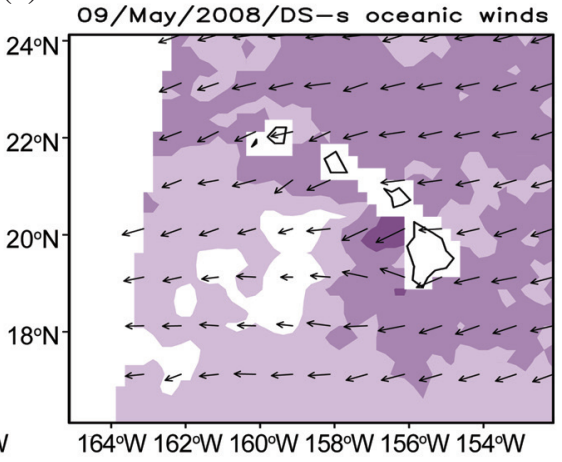


(a)

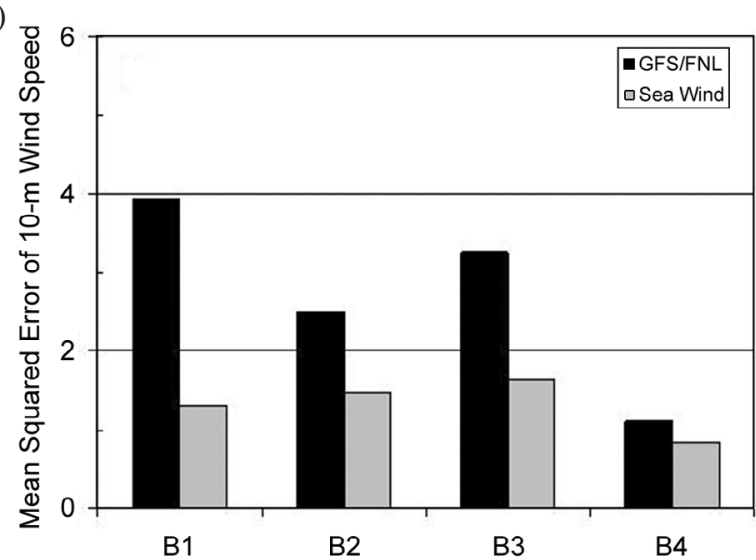

(b)

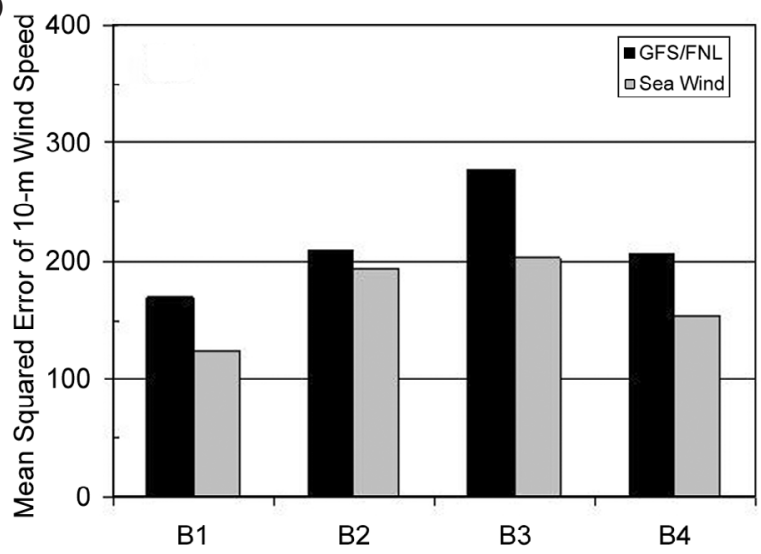

Fig. 16. The mean squared error (MSE) in predicted 24-hr (a) 10-m wind speed, and (b) 10-m wind direction from the average of four events. The black and grey bars represent the MSE by the GFS or NCEP-FNL runs and the simulations with the assimilated QuikSCAT ocean surface winds, respectively.
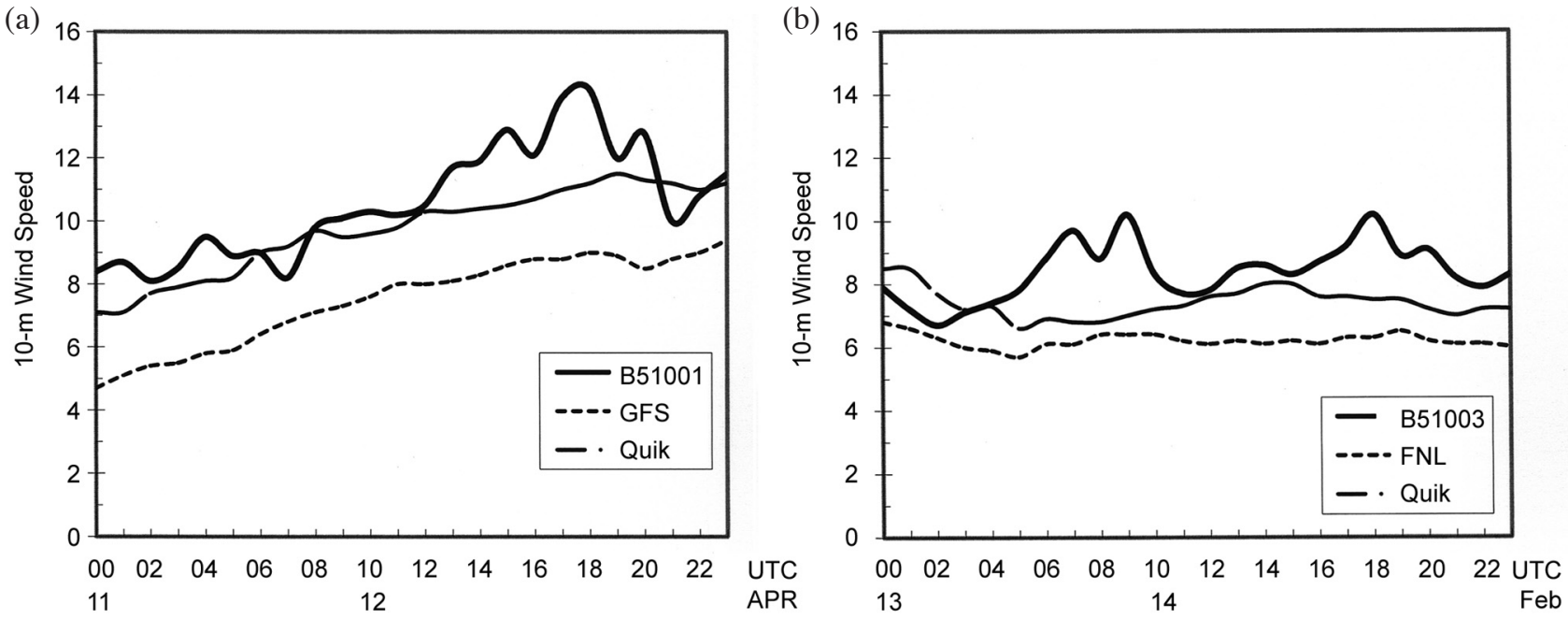

Fig. 17. The predicted 24-hr 10-m wind speed $\left(\mathrm{m} \mathrm{s}^{-1}\right)$ at the buoy 1 for a surface cold front event (a) and at the buoy 3 for a strong wind event (b). In (a), the buoy 1 observations, GFS and QuikSCAT runs are represented by the solid, the dotted, and the dash-dotted line respectively. In (b), the buoy 3 observations, NCEP-FNL and QuikSCAT runs are represented by the solid, the dotted, and the dash-dotted line respectively.

the associated high-pressure system with an anticyclonic circulation over the ocean can be seen in the analyzed oceanic winds. The stronger easterly/northeasterly winds $\left(>10 \mathrm{~m} \mathrm{~s}^{-1}\right)$ over the Hawaiian Islands and the surrounding ocean, consistent with the apparent pressure gradient there, are also revealed by the analyzed oceanic winds one day before the damaging winds are observed over land in the Hawaiian Islands during 14 - 15 February 2001. During a trade-wind day on 8 May 2008, the dominant subtropical high pressure accompanied by anticyclonic circulation is shown through the QuikSCAT winds. The associated prevailing easterly-to-northeasterly winds are also revealed over the open ocean.

For the impact of the assimilated QuikSCAT winds on the prediction of near-ocean surface winds, the initial 1000-
$\mathrm{hPa}$ winds show a significant increase of the wind speed in the Hawaiian Island chain and the surrounding ocean as compared with the GFS analysis and NCEP-FNL reanalysis under different weather conditions. This indicates that the incorporation of the QuikSCAT winds can improve the under-estimation of the near-ocean surface winds by the global analysis and reanalysis in the Hawaiian Island chain. In addition, orographic effects of the Hawaiian Islands on near-ocean surface winds can be reproduced by the numerical predictions with assimilated with QuikSCAT winds, which did not capture well in the satellite-derived ocean surface winds and the global analyses. To statistically evaluate the predicted $10-\mathrm{m}$ winds during the $24-\mathrm{hr}$ predictions with assimilated oceanic winds and GFS/NCEP-FNL run, the results indicate that the incorporation of the analyzed 
QuikSCAT winds by WRF 3D-Var can improve the prediction of near-ocean surface winds. For the 10-m wind speed forecasting with oceanic wind assimilation, the statistical errors primarily decrease in the cold front and the strongwind events near buoys 1,2 and 3. The statistical errors for the predicted $10-\mathrm{m}$ wind direction near four buoys are also reduced with the assimilation of oceanic winds. However, the limited number of cases and data limitations may not be enough to completely draw a strong conclusion about the impact of satellite-derived ocean surface winds on the prediction of near-ocean surface winds around Hawaii. As a preliminary analysis, the results presented here are significant for use in future studies.

Acknowledgments Thanks to the NASA Ocean Vector Winds Science Team which sponsored and provided the QuikSCAT satellite-derived ocean surface winds through Remote Sensing System. Data are available at www.remss. com. Also, thanks to NCAR MMM for providing the WRF 3D-Var system and to Prof. Yi-Leng Chen as well as anonymous reviewers for valuable suggestions. This research is supported by the Hawaiian Pacific Ocean Observing Information System (HI-POOIS) project and Joint Institute for Marine and Atmospheric Research (JIMAR).

\section{REFERENCES}

Atlas, R., R. N. Hoffman, S. M. Leidner, J. Sienkiewicz, T. W. Yu, S. C. Bloom, E. Brin, J. Ardizzone, J. Terry, D. Bungato, and J. C. Jusem, 2001: The effects of marine winds from scatterometer data on weather analysis and forecasting. Bull. Amer. Meteorol. Soc., 82, 19651990, doi: 10.1175/1520-0477(2001)082<1965:TEOM $\mathrm{WF}>2.3 . \mathrm{CO} ; 2$. [Link]

Barker, D. M., W. Huang, Y. R. Guo, J. Bourgeois, and Q. N. Xiao, 2004: A three-dimensional variational data assimilation system for MM5: Implementation and initial results. Mon. Weather Rev., 132, 897-914, doi: 10.1175/1520-0493(2004)132<0897:ATVDAS>2.0. CO;2. [Link]

Chelton, D. B. and M. H. Freilich, 2005: Scatterometerbased assessment of 10-m wind analyses from the operational ECMWF and NCEP numerical weather prediction models. Mon. Weather Rev., 133, 409-429, doi: 10.1175/MWR-2861.1. [Link]

Chelton, D. B., M. H. Freilich, J. M. Sienkiewicz, and J. M. Von Ahn, 2006: On the use of QuikSCAT scatterometer measurements of surface winds for marine weather prediction. Mon. Weather Rev., 134, 2055-2071, doi: 10.1175/MWR3179.1. [Link]

Chen, F. and J. Dudhia, 2001: Coupling an advanced land surface-hydrology model with the Penn State-NCAR MM5 modeling system. Part I: Model implementation and sensitivity. Mon. Weather Rev., 129, 569-585, doi:
10.1175/1520-0493(2001)129<0569:CAALSH>2.0. CO;2. [Link]

Donnelly, W. J., J. R. Carswell, R. E. McIntosh, P. S. Chang, J. Wilkerson, F. Marks, and P. G. Black, 1999: Revised ocean backscatter models at $\mathrm{C}$ and $\mathrm{Ku}$ band under highwind conditions. J. Geophys. Res., 104, 11485-11497, doi: 10.1029/1998JC900030. [Link]

Dudhia, J., 1989: Numerical study of convection observed during the winter monsoon experiment using a mesoscale two-dimensional model. J. Atmos. Sci., 46, 30773107, doi: 10.1175/1520-0469(1989)046<3077:NSOC OD>2.0.CO;2. [Link]

Ferrier, B. S., Y. Jin, Y. Lin, T. Black, E. Rogers, and G. DiMego, 2002: Implementation of a new grid-scale cloud and precipitation scheme in the NCEP Eta model. Preprints, $15^{\text {th }}$ Conf. on Numerical Weather Prediction, San Antonio, TX, Amer. Meteor. Soc., 280-283.

Huddleston, J. N. and B. W. Stiles, 2000: Multidimensional histogram (MUDH) rain flag. Product description (version 3.0), Jet Propulsion Laboratory, Pasadena, $\mathrm{CA}, 17 \mathrm{pp}$.

Isaksen, L. and P. A. E. M. Janssen, 2004: Impact of ERS scatterometer winds in ECMWF's assimilation system. Q. J. R. Meteorol. Soc., 130, 1793-1814, doi: 10.1256/ qj.03.110. [Link]

Janjić, Z. I., 1994: The step-mountain eta coordinate model: Further developments of the convection, viscous sublayer and turbulence closure schemes. Mon. Weather Rev., 122, 927-945, doi: 10.1175/1520-0493(1994)12 $2<0927$ :TSMECM $>2.0 . \mathrm{CO} ; 2$. [Link]

Janjić, Z. I., 2000: Comments on "Development and evaluation of a convection scheme for use in climate models." J. Atmos. Sci., 57, 3686.

Kodama, K. R. and S. Businger, 1998: Weather and forecasting challenges in the Pacific region of the National Weather Service. Weather Forecast., 13, 523-546, doi: 10.1175/1520-0434(1998)013<0523:WAFCIT>2.0. CO;2. [Link]

Leidner, S. M., L. Isaksen, and R. N. Hoffman, 2003: Impact of NSCAT winds on tropical cyclones in the ECMWF 4DVAR assimilation system. Mon. Weather Rev., 131, 3-26, doi: 10.1175/1520-0493(2003)131<0003:IONW OT>2.0.CO;2. [Link]

Liu, K. S. and J. C. L. Chan, 1999: Size of tropical cyclones as inferred from ERS-1 and ERS-2 data. Mon. Weather Rev., 127, 2992-3001, doi: 10.1175/1520-0493(1999)1 27<2992:SOTCAI >2.0.CO;2. [Link]

Liu, W. T., W. Tang, and P. S. Polito, 1998: NASA scatterometer provides global ocean-surface wind fields with more structures than numerical weather prediction. Geophys. Res. Lett., 25, 761-764, doi: 10.1029/ 98GL00544. [Link]

Liu, W. T., H. Hu, and S. Yueh, 2000: Interplay between wind and rain observed in Hurricane Floyd. Eos, 
Trans., AGU, 81, 253-257, doi: 10.1029/00EO00177. [Link]

Maddox, R., 1980: An objective technique for separating macroscale and mesoscale features in meteorological data. Mon. Weather Rev., 108, 1108-1121, doi: 10.11 75/1520-0493(1980)108<1108:AOTFSM>2.0.CO;2. [Link]

Mlawer, E. J., S. J. Taubman, P. D. Brown, M. J. Iacono, and S. A. Clough, 1997: Radiative transfer for inhomogeneous atmospheres: RRTM, a validated correlated-k model for the longwave. J. Geophys. Res., 102, 1666316682, doi: 10.1029/97JD00237. [Link]

Parrish, D. F. and J. C. Derber, 1992: The national meteorological center's spectral statistical-interpolation analysis system. Mon. Weather Rev., 120, 1747-1763, doi: 10.1175/1520-0493(1992)120<1747:TNMCSS $>2.0$. $\mathrm{CO} ; 2$. [Link]

Portabella, M. and A. Stoffelen, 2004: A probabilistic approach for SeaWinds data assimilation. Q. J.R. Meteorol. Soc., 130, 127-152, doi: 10.1256/qj.02.205. [Link]

Schroeder, T. A., 1977: Severe downslope winds on Oahu. Preprints, $10^{\text {th }}$ Conf. on Severe Local Storms, Omaha, NE, Amer. Meteor. Soc., 373-375.

Schroeder, T. A., 1993: Climate controls. In: Sanderson, M. (Ed.), Prevailing Trade Winds, University of Hawaii Press, Honolulu, 12-36.

Sharp, R. J., M. A. Bourassa, and J. J. O'Brien, 2002: Early detection of tropical cyclones using seawinds-derived vorticity. Bull. Amer. Meteorol. Soc., 83, 879-889, doi: 10.1175/1520-0477(2002)083<0879:EDOTCU>2.3. CO;2. [Link $]$

Simpson, R. H., 1952: Evolution of the Kona storm, a subtropical cyclone. J. Meteorol., 9, 24-35, doi: 10.1175/ 1520-0469(1952)009<0024:EOTKSA>2.0.CO;2. [Link]

Skamarock, W. C., 2005: Time splitting techniques for multidimensional transport, $26 \mathrm{pp}$.

Skamarock, W. C., J. B. Klemp, J. Dudhia, D. O. Gill, D. M. Barker, M. G. Duda, X. Y. Huang, W. Wang, and J. G. Powers, 2008: A Description of the Advanced Research WRF Version 3. NCAR Technical Note, NCAR/ TN-475+STR, 113 pp, Mesoscale and Microscale Meteorology Division, National Center for Atmospheric Research, Boulder, Colorado, USA.
Smith, R. B. and V. Grubišić, 1993: Aerial observations of Hawaii's wake. J. Atmos. Sci., 50, 3728-3750, doi: 10.1175/1520-0469(1993)050<3728:AOOHW >2.0. $\mathrm{CO}$;2. [Link]

Smolarkiewicz, P. K., R. M. Rasmussen, and T. L. Clark, 1988: On the dynamics of Hawaiian cloud bands: Island forcing. J. Atmos. Sci., 45, 1872-1905, doi: 10.11 75/1520-0469(1988)045<1872:OTDOHC>2.0.CO;2. [Link]

Stiles, B. W. and S. H. Yueh, 2002: Impact of rain on spaceborne Ku-band wind scatterometer data. IEEE Trans. Geosci. Remote Sensing, 40, 1973-1983, doi: 10.1109/ TGRS.2002.803846. [Link]

Wilks, D. S., 2006: Statistical methods in the Atmospheric Sciences. Academic Press, 627 pp.

Xiao, Q. and J. Sun, 2007: Multiple-radar data assimilation and short-range Quantitative Precipitation Forecasting of a squall line observed during IHOP_2002. Mon. Weather Rev., 135, 3381-3404, doi: 10.1175/MWR34 71.1. [Link]

Xiao, Q., X. Zhang, C. Davis, J. Tuttle, G. Holland, and P. J. Fitzpatrick, 2009: Experiments of hurricane initialization with airborne Doppler radar data for the Advanced-research Hurricane WRF (AHW) model. Mon. Weather Rev., 137, 2758-2777, doi: 10.1175/20 09MWR2828.1. [Link]

Yang, Y., Y. L. Chen, and F. M. Fujioka, 2005: Numerical simulations of the island-induced circulations over the Island of Hawaii during HaRP. Mon. Weather Rev., 133, 3693-3713, doi: 10.1175/MWR3053.1. [Link]

Yeh, H. C. and G. T. J. Chen, 2004: Case study of an unusual heavy rain event over Eastern Taiwan during the Mei-Yu Season. Mon. Weather Rev., 132, 320-337, doi: 10.1175/1520-0493(2004)132<0320:CSOAUH> 2.0.CO;2. [Link]

Yeh, H. C., G. T. J. Chen, and W. T. Liu, 2002: Kinematic characteristics of a Mei-yu front detected by the QuikSCAT oceanic winds. Mon. Weather Rev., 130, 700711, doi: 10.1175/1520-0493(2002)130<0700:KCOA MY>2.0.CO;2. [Link]

Zhang, Y., Y. L. Chen, and K. Kodama, 2005: Validation of the coupled NCEP mesoscale spectral model and an advanced land surface model over the Hawaiian Islands. Part II: A high wind event. Weather Forecast., 20, 873-895, doi: 10.1175/WAF892.1. [Link] 